\title{
FLAT PLATE FILM COOLING WITH LINEAR AND CURVED ROUND-TO- DIFFUSION SHAPED SLOTS USING PSP MEASUREMENT TECHNIQUE
}

\author{
A Thesis \\ by \\ IZHAR ULLAH \\ Submitted to the Office of Graduate and Professional Studies of \\ Texas A\&M University \\ in partial fulfillment of the requirements for the degree of \\ MASTER OF SCIENCE
}

$\begin{array}{ll}\text { Chair of Committee, } & \text { Je Chin Han } \\ \text { Committee Members, } & \begin{array}{l}\text { Yassin Hassan } \\ \text { Michael Pate }\end{array} \\ \text { Head of Department, } & \text { Andreas Polycarpou }\end{array}$

August 2018

Major Subject: Mechanical Engineering

Copyright 2018 Izhar Ullah 


\begin{abstract}
This thesis is an experimental study to examine the effect of different hole shapes and coolant hole trajectory on film cooling effectiveness and discharge coefficient. PSP technique was used to calculate the film cooling effectiveness and film cooling contours. Effect of hole geometry and trajectory was studied at different density ratios and different blowing ratios. Three different density ratios $\mathrm{DR}=1, \mathrm{DR}=1.5$ and $\mathrm{DR}=2$ were used and five blowing ratios from $\mathrm{M}=0.5-1.5$ were used with an increment of 0.25 . Diameter of the hole was taken as $4 \mathrm{~mm}$. Three different exit geometries (Round to slot-, Round to annulus, Round to annulus2) were used with linear and projectile trajectories, thus making a total of six test plates.

Results obtained agreed with the general trend of shaped holes. It is interesting to observe that slot shaped exit hole is still a better option than annulus shaped holes. Slot shaped exit hole with projectile trajectory resulted in improved effectiveness with $30-40 \%$ increase in span wise effectiveness as compared to its linear slot shaped counterpart. This improved design at $\mathrm{DR}=2$ which corresponds to the actual conditions of a real engine. However round to slot test plate with projectile trajectory has the lowest discharge coefficient implying more pressure requirement for the coolant at the same blowing ratio. Correlation was obtained for a single row different exit shaped holes.
\end{abstract}




\section{DEDICATION}

I dedicate this thesis to my parents, Maulana Tariq Jameel and late Junaid

Jamshed (R.A). The reason for dedication is their profound impact on my life. 


\section{ACKNOWLEDGEMENTS}

I would like to thank my committee chair, Dr. J C Han for his continuous support and guidance through-out my whole master's program in general and my thesis in particular, without his support my degree program would never have been completed.

I would also like to thank my committee members, Dr. Yassin Hassan and Dr. Michele B Pate for their valuable time, support and service as my thesis committee members.

I also would like to thank my colleagues at the Turbine Heat Transfer Lab for their support, especially Dr. Joe and for his technical and non-technical help.

In addition, I also want to thank Garrick Gaza and Andrew from Physic machines shop for having my test plates ready in the quickest possible time without any delay.

Finally, thanks to my parents for their encouragement and prayers and continuous support and motivation through my studies which will continue as well in the times to come. 


\section{CONTRIBUTORS AND FUNDING SOURCES}

This work is supported by a thesis committee consisting of Professor Je Chin Han and Professor Michael Pate of the Department of Mechanical Engineering and Professor Yassin A. Hassan of the Department of Nuclear Engineering.

The data analyzed for section 3.7 "Correlation for Single Row Shaped Holes" was

provided by Dr. Joe. All other work conducted for the thesis was completed by the student independently.

Graduate study was supported by a fellowship from the Fulbright Scholarship Program and a thesis research fellowship from Marcus Easterling Endowment Fund. 


\section{NOMENCLATURE}

$\alpha$

$\eta$

$\rho$

C

D

DR

I

M

P

$\mathrm{T}$

$\mathrm{Tu}$

Z

\begin{tabular}{ll}
\multicolumn{2}{c}{ Subscript } \\
$\alpha$ & Mainstream air property \\
aw & Adiabatic Wall \\
blk & Black Condition \\
ref & Reference Condition
\end{tabular}

Subscript

$\alpha$ 


\section{TABLE OF CONTENTS}

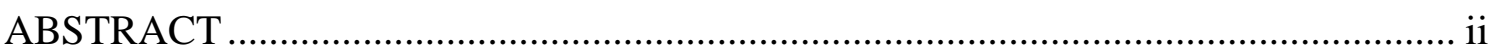

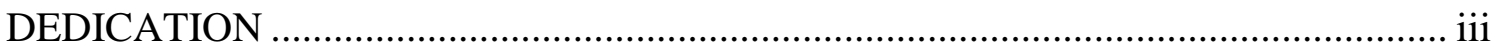

ACKNOWLEDGEMENTS ……………………………...............................................

CONTRIBUTORS AND FUNDING SOURCES.....................................................

NOMENCLATURE ..........................................................................................vi

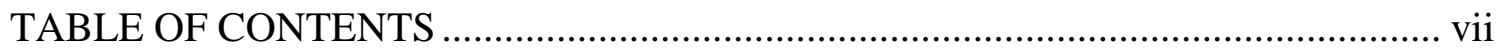

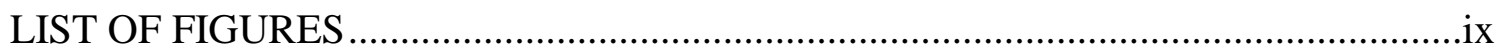

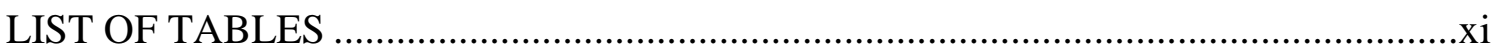

1. INTRODUCTION \& LITERATURE SURVEY ……….........................................

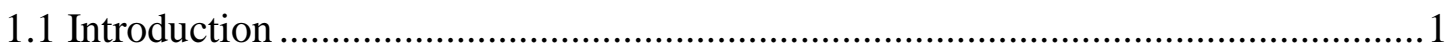

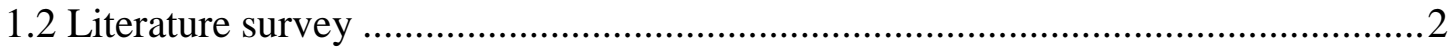

2. EXPERIMENTAL SETUP \& PROCEDURE ………………...............................6

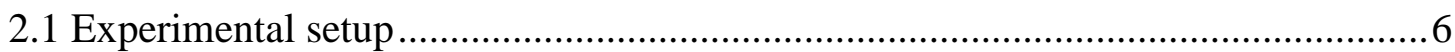

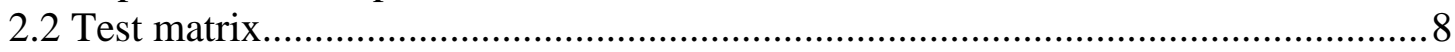

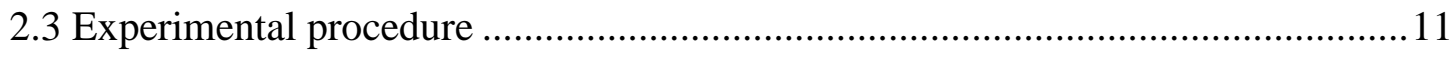

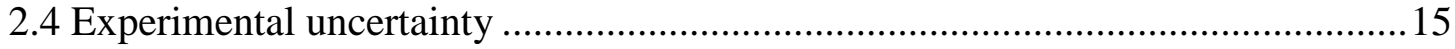

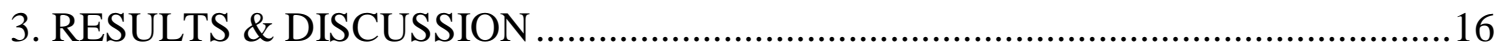

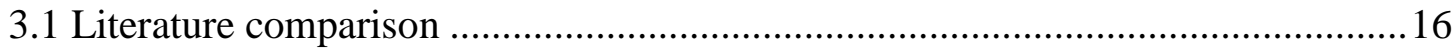

3.2 Blowing ratio effect....................................................................................

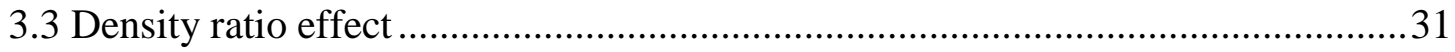

3.4 Exit hole shape and coolant trajectory effect on film effectiveness........................38

3.5 Area averaged effectiveness..............................................................................42

3.6 Exit hole shape and coolant trajectory effect on Discharge Coefficient ..................46

3.7 Correlation for Single Row Shaped Holes ..............................................................4

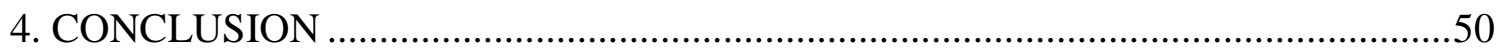

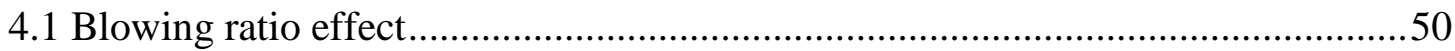

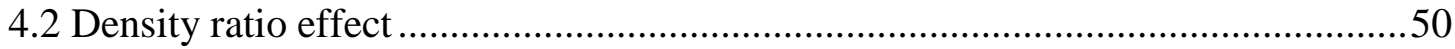


4.3 Exit hole shape and coolant trajectory effect on film effectiveness .....................50

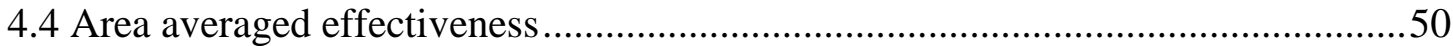

4.5 Exit hole shape and coolant trajectory effect on Discharge Coefficient ...............51

4.6 Correlation for Single Row Shaped Holes ......................................................51

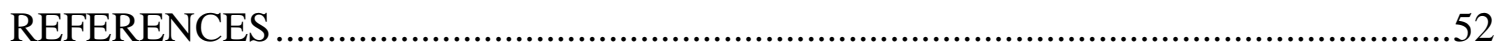

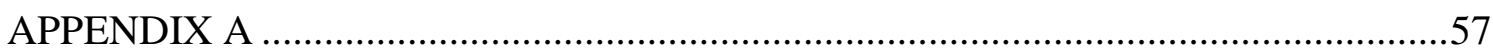




\section{LIST OF FIGURES}

Figure 1: Typically cooled airfoil blade (Ekkad et al [3] ) ............................................. 1

Figure 2: Schematic diagram for experimental setup..............................................6

Figure 3: Solid works model showing the test plate with coolant and mainstream flow...7

Figure 4: (a) Left to Right: Round to Slot-Linear (R-S-L), Round to Annulus-Linear (R-A-L), Round to Annulus2-Linear (R-A2-L), (b) Cross sectional view showing the linear trajectory profile....

Figure 5: (a) Left to Right: Round to Slot-Projectile (R-S-P), Round to AnnulusProjectile (R-A-P), Round to Annulus2-Projectile (R-A2-P), (b) Cross sectional view showing the projectile trajectory profile.

Figure 6: Calibration setup

Figure 7: Calibration curve

Figure 8: Round to Slot-Linear test plate comparison with open literature ( An et al [21])

Figure 9: Round to Slot-Linear test plate comparison with open literature ( An et al [21])

Figure 10: Film cooling effectiveness data for all the shapes for $\mathrm{DR}=1$

Figure 11: Film cooling effectiveness data for all the shapes for $\mathrm{DR}=1.5$

Figure 12: Film cooling effectiveness data for all the shapes for $\mathrm{DR}=2$

Figure 13:Film cooling effectiveness contours for linear trajectory hole design at

$\mathrm{DR}=1$

Figure 14: Film cooling effectiveness contours for projectile trajectory contours at

$\mathrm{DR}=1$

Figure 15:Film cooling effectiveness contours for linear trajectory contours at $\mathrm{DR}=1.5$. .26

Figure 16:Film cooling effectiveness contours for projectile trajectory contours at $\mathrm{DR}=1.5$. 
Figure 17:Film cooling effectiveness contours for linear trajectory contours at DR=2...28

Figure 18:Film cooling effectiveness contours for projectile trajectory contours at $\mathrm{DR}=2$. 29

Figure 19: Formation of kidney and anti-kidney vortices for all the shapes.....................30

Figure 20: Density ratio effect on span wise film cooling effectiveness for R-S-L..........32

Figure 21:Density ratio effect on span wise film cooling effectiveness for R-S-P..........33

Figure 22: Density ratio effect on span wise film cooling effectiveness for R-A-L........34

Figure 23: Density ratio effect on span wise film cooling effectiveness for R-A2-L ......35

Figure 24: Density ratio effect on span wise film cooling effectiveness for R-A-P ........36

Figure 25: Density ratio effect on span wise film cooling effectiveness for R-A2-P ......37

Figure 26:Effect of exit hole shape and the coolant trajectory on film cooling effectiveness for $\mathrm{DR}=1$

Figure 27:Effect of exit hole shape and the coolant trajectory on film cooling effectiveness for $\mathrm{DR}=1.5$

Figure 28: Effect of exit hole shape and the coolant trajectory on film cooling effectiveness for $\mathrm{DR}=2$

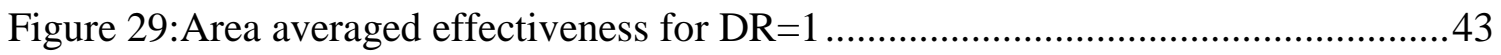

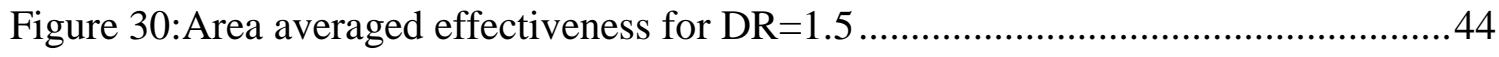

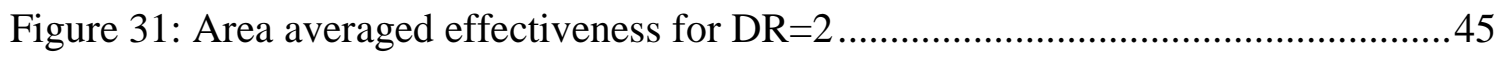

Figure 32: Discharge Coefficient variation with blowing ration and pressure ratio for all the plates 


\section{LIST OF TABLES}

Table 1: Mainstream flow conditions for the setup....................................................

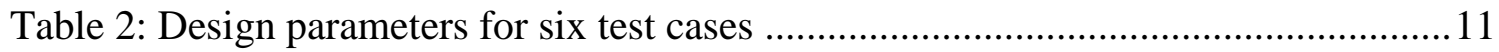

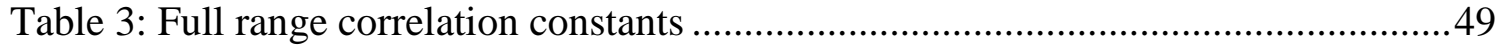

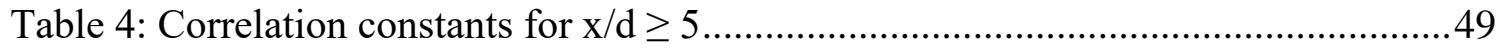




\section{INTRODUCTION \& LITERATURE SURVEY}

\subsection{Introduction}

Turbine rotor inlet temperature (RIT) is showing increasing trend in its value for the purpose of increasing efficiency in gas turbine engine. Due to limited development of high strength material for high temperature range of $1700 \mathrm{C}$ [1], internal and external cooling is used to maintain the temperature of the turbine blades in acceptable limits. External cooling normally referred to as film cooling is carried out by injecting a secondary fluid at one or more surface of gas turbine blade exposed to high temperature [2]. Film cooling is greatly dependent on many parameters including but not limited to film cooling hole geometry, mainstream to coolant blowing ratio, mainstream to coolant density ratio, mainstream turbulence and Mach number of mainstream and coolant.

Figure.1 shows a typically cooled airfoil of a gas turbine engine.

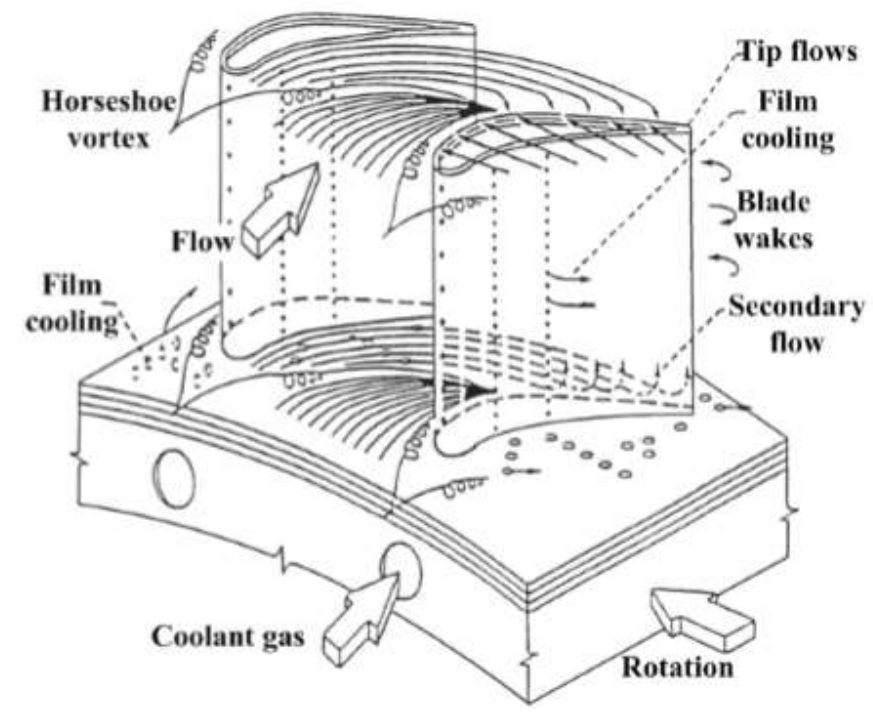

Figure 1: Typically cooled airfoil blade (Ekkad et al [3] ) 


\subsection{Literature survey}

One of the main parameters that affects the film cooling performance is the film cooling hole geometry. Studies have always focused on innovative shaped holes mainly aimed at reducing the exit momentum of the coolant to get better film effectiveness as well as better coverage. Manufacturing of different shaped holes is made easy with the recent advancement of technology of 3d printing. Ekkad et al [3] and Bunker et al [4] provided the summary of most common types of film cooling hole geometry used since inception. Eckert et al [5] and Goldstein et al [6] study focuses on reducing the exit momentum of the coolant so that the coolant is attached to the surface which will result in greater effectiveness. The effectiveness of cylindrical hole is the same as fan shaped for $\mathrm{M}=0.5$ blowing ratio but for higher blowing ratios the effectiveness of fan shaped is greater due less lift off of the coolant which implies the essential effect of exit hole shaping on film cooling effectiveness. Makki and Jakubowski [7] studied the effect of exit hole shape by introducing trapezoidal exit hole shape, result showed that the overall film cooling effectiveness increases as compared of cylindrical hole. Thole et al [8] and Gritsch et al [9] also studied the effect of expanded hole exits as compared to cylindrical holes. Hyams et al [10] studied different holes computationally which included cylindrical film hole, forward diffused film hole, laterally diffused film hole, inlet shaped film hole and cusp shaped film hole. It was found that the laterally diffused film hole provides the best coverage and highest effectiveness. Sargison et al [11,12] studied a new film cooling hole geometry called converging slot hole or console. Results suggested better film coverage and less aerodynamics loss. Following Sargison many studies were conducted 
on rectangular shaped film cooling hole also known as slot shaped cooling hole. Moser et al [13] studied a new approach using transonic wall film jets for blade cooling. Fric and Campbell [14] and Bunker [15] studied cratered film hole and a trenched hole respectively in which the inlet circular hole expands to a circular hole with a depression. The advantage of this hole is that the depression fills up first before exiting the hole. This resulted in 50 - $100 \%$ increase as compared to circular holes. Nasir et al [16] also studied round film holes having triangular tabs at the upstream of the hole helping in reduction of coolant lift off increasing the effectiveness as compared to cylindrical holes. Lu et al $[17,18]$ studied experimentally film cooling from cylindrical holes embedded in transverse trench trenches and craters. Lee et al [19] studied a novel shaped hole numerically and compared it with performance of fan shaped hole. Yang et al [20] also studied three different exit shapes (bean shaped, clover head, winter sweet (shaped hole) and found that bean shaped hole is the best option as compared to cylindrical holes. An B et al [21] recently studied different rectangular shaped holes with different aspect ratios and diffusion angle experimentally using PSP technique on flat plate. Results suggested that the effectiveness increases with increasing the aspect ratio and the blowing ratio. He observed different film distribution at different aspect ratios and the effect of anti- kidney vortices formation. Abdala et al [22] studied annular shaped exit hole computationally and found that the effectiveness of annular film hole increases to significantly as compared to rectangular and circular film cooling holes.

Generally, film cooling effectiveness as well as discharge coefficient is dependent on the coolant inlet conditions as well the passage way (coolant trajectory). Discharge 
coefficient is the measure of flow through film cooling hole as compared to its ideal mass flow. Goldstein et al [6] studied the entrance effect of the passage way on the film cooling effectiveness by using a long cylindrical entrance to create a $\alpha=90^{\circ}$ inlet condition for cylindrical holes. Gritch et al [23] results also suggested that fan shaped holes has better discharge coefficient than cylindrical holes and that discharge coefficient is dependent on inlet conditions. Kohli and Thole [24,25] also studied entrance effect. Results suggested that coolant channel orientation and the coolant passage way played a significant role in effectiveness distribution and the discharge coefficient. Burd et al [26] studied the effect of six different entrance conditions (hole length and coolant supply geometry) on the discharge coefficient. He found that cooling hole with shorter length has higher discharge coefficient due to interaction with the free stream flow. Taslim et al [27] research dealt with different conical shaped film cooling holes with $\alpha=0^{\circ}, \alpha=30^{\circ}, \alpha=45^{\circ}$ and $\alpha=60^{\circ}$. Discharge coefficient of these different holes were compared with cylindrical holes with $\alpha=90^{\circ}$. He concluded that at high pressure ratios the conical film cooling hole has higher discharge coefficient as compared to cylindrical. Results also suggested that as the inclination decreases, the discharge coefficient increases. Zuniga et al [28] also studied the effect of different conical shaped film cooling hole on effectiveness and distribution. He concluded that conical shape has higher discharge coefficient as compared to cylindrical holes while the effectiveness distribution is almost the same as fan shaped holes. Recently Zhang et al [29] investigated computationally and experimentally different round to slots configuration with $\alpha=35^{\circ}$ and different $s / d$ (slot width), he concluded that the diffusion round to slot geometry is more favorable close to the exit hole 
while the converging slot is better as we go further downstream of the exit hole. He also concluded that discharge coefficient decreases as the slot width is decreased.

Generally for cylindrical holes the effectiveness increases with blowing ratio up to some extend i-e $\mathrm{M}=0.5$ after which it reduces due to coolant lift off [5] while for fan shaped holes the effectiveness increases as the blowing ratio is increased [5,6,21, 32].In gas turbine engine, typically the coolant to mainstream density ration (DR) is close to 2 which is caused by the temperature difference between the coolant and the mainstream flow. Heat transfer and mass transfer technique (under the assumption of turbulent Lewis number equals 1) [30] are two techniques to see the density ratio effect. In general, the film cooling effectiveness increases with increase in density ratios except at low blowing ratios $[3,7]$

The objective of this study is to determine on the effect of hole shape, coolant trajectory, blowing ratio and density ratio on the film cooling effectiveness. Discharge coefficient is also measured because little or no data for these new geometries is available in open literature. 


\section{EXPERIMENTAL SETUP \& PROCEDURE}

\subsection{Experimental setup}

Experiment is carried out in a low speed suction type wind tunnel as shown in Figure 2. Mainstream velocity is kept as $21.8 \mathrm{~m} / \mathrm{s}$ while the Reynolds number is maintained at 285,000. A turbulence grid is used to keep $6 \%$ turbulence intensity. Coolant is fed using three different cylinders of $\mathrm{N}_{2}(\mathrm{DR}=1), \mathrm{CO}_{2}(\mathrm{DR}=1.5)$ and a mixture $(\mathrm{DR}=2)$. Table 1 gives the mainstream conditions of the setup while Figure 3 is a solid work model showing the test plates and the coolant inlet and external flow path. Coolant is fed through Dwyer rotameters to maintain the desired blowing ratio. Inlet coolant plenum pressure is measured using pressure taps at the inlet plenum while the mainstream static pressure and velocity is measured using a pitot static tube $z / d=55$ downstream of the turbulence grid. Detail description of the test section can be found in Bashir et al [33]. LED is used to excite the PSP on the test plate. Results are captured using a CCD camera.

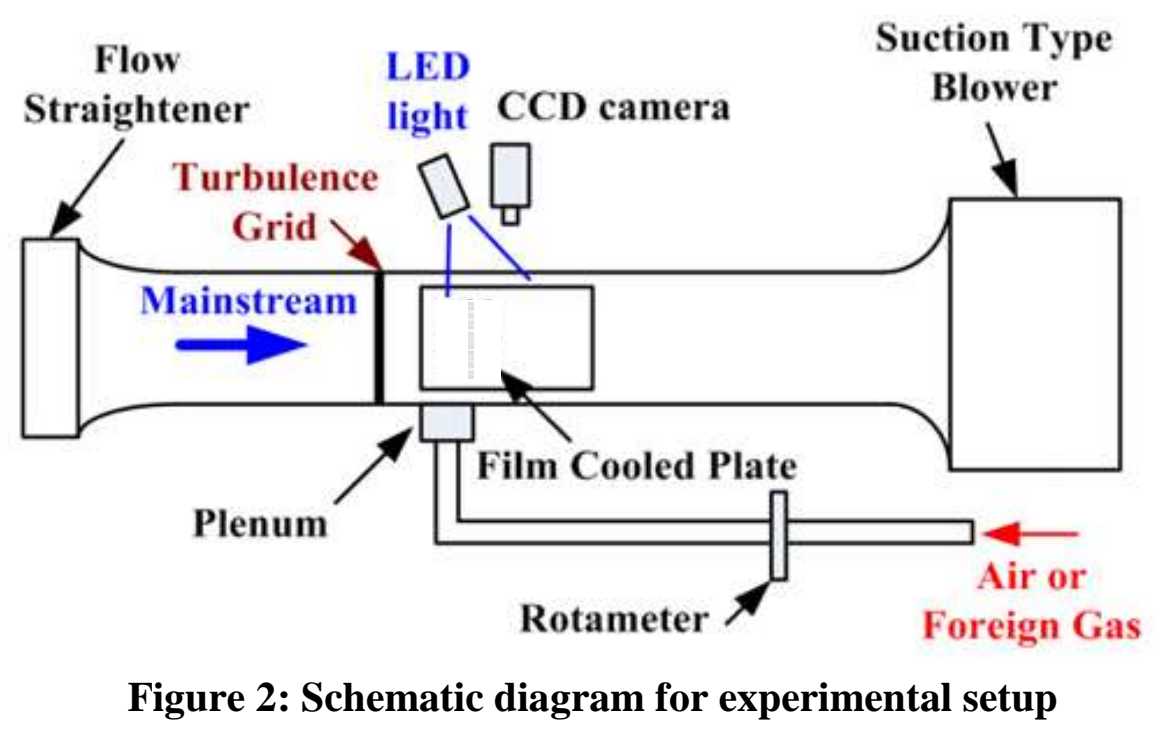




\begin{tabular}{|c|c|}
\hline Property & Value \\
\hline Density & $1.18 \mathrm{~kg} / \mathrm{m}^{3}$ \\
\hline Temperature & $297 \mathrm{~K}$ \\
\hline Velocity & $21.82 \mathrm{~m} / \mathrm{s}$ \\
\hline $\operatorname{Re}$ (based on hydraulic diameter) & 285,000 \\
\hline Tu & $6 \%$ \\
\hline
\end{tabular}

Table 1: Mainstream flow conditions for the setup

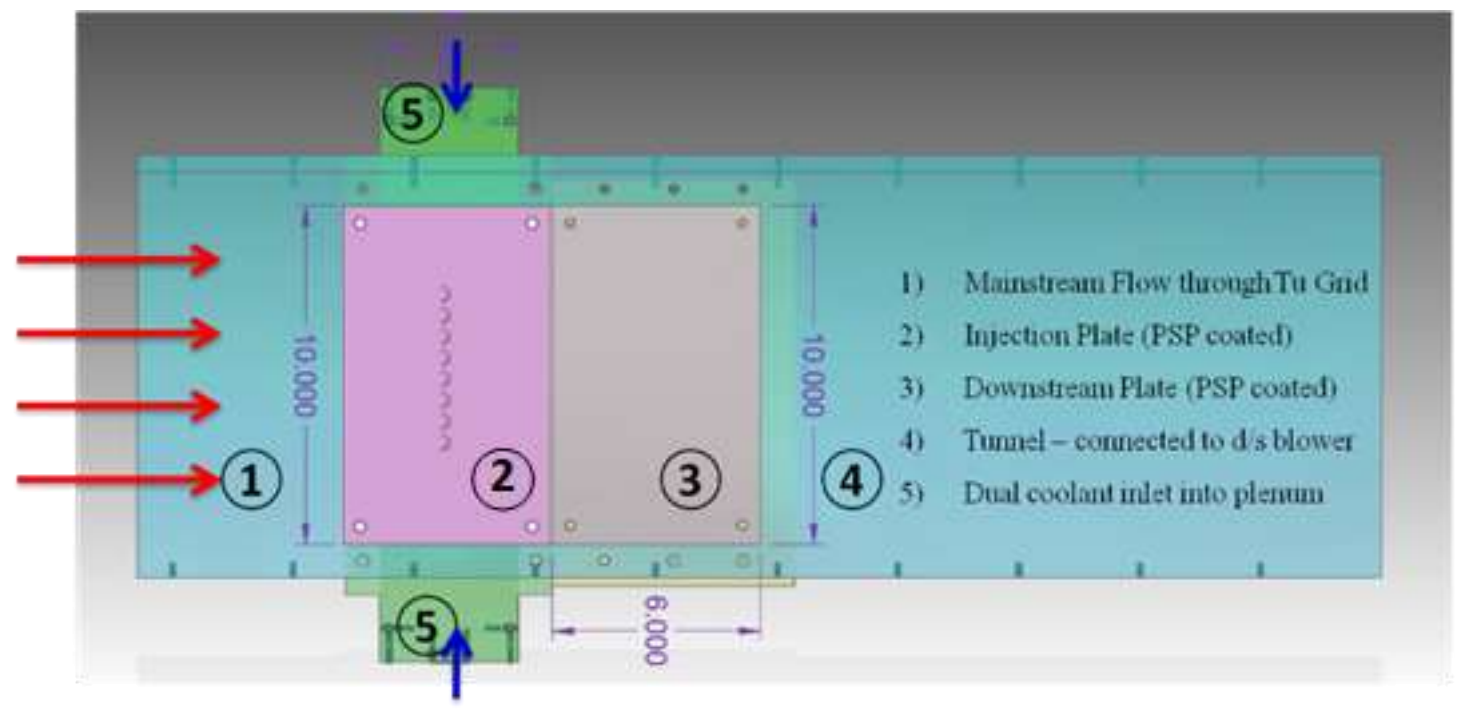

Figure 3: Solid works model showing the test plate with coolant and mainstream flow 


\subsection{Test matrix}

Six plates are 3D printed having three different exit shapes and two different coolant trajectories (Linear and Projectile). Base material for all the plates is Acura extreme white. Figure 4 and Figure 5 shows the design of all the six plates. Inlet hole diameter is $4 \mathrm{~mm}$. Figure 4(a): Left to right is Round to Slot Linear (R-S-L), Round to Annulus Linear (R-A-L) and Round to Annulus 2 Linear (R-A2-L) while Figure 4(b) shows the cross section of the linear trajectory with inlet angle, $\alpha=30^{\circ}$. Similarly Figure 5(a): Right to left shows the projectile trajectory profile plates Round to Slot Projectile (R-S-P), Round to Annulus Projectile (R-A-P) and Round to Annulus 2 Projectile (RA2-P) while Figure 5(b) is showing the cross section of the projectile trajectory with inlet angle, $\alpha=90^{\circ}$. Test is run with 5 different blowing ratios from 0.5 to 1.5 with three different blowing ratios $\mathrm{DR}=1,1.5$ and 2 making a total of 90 test cases. Design data for all the six plates are summarized in Table 2. 


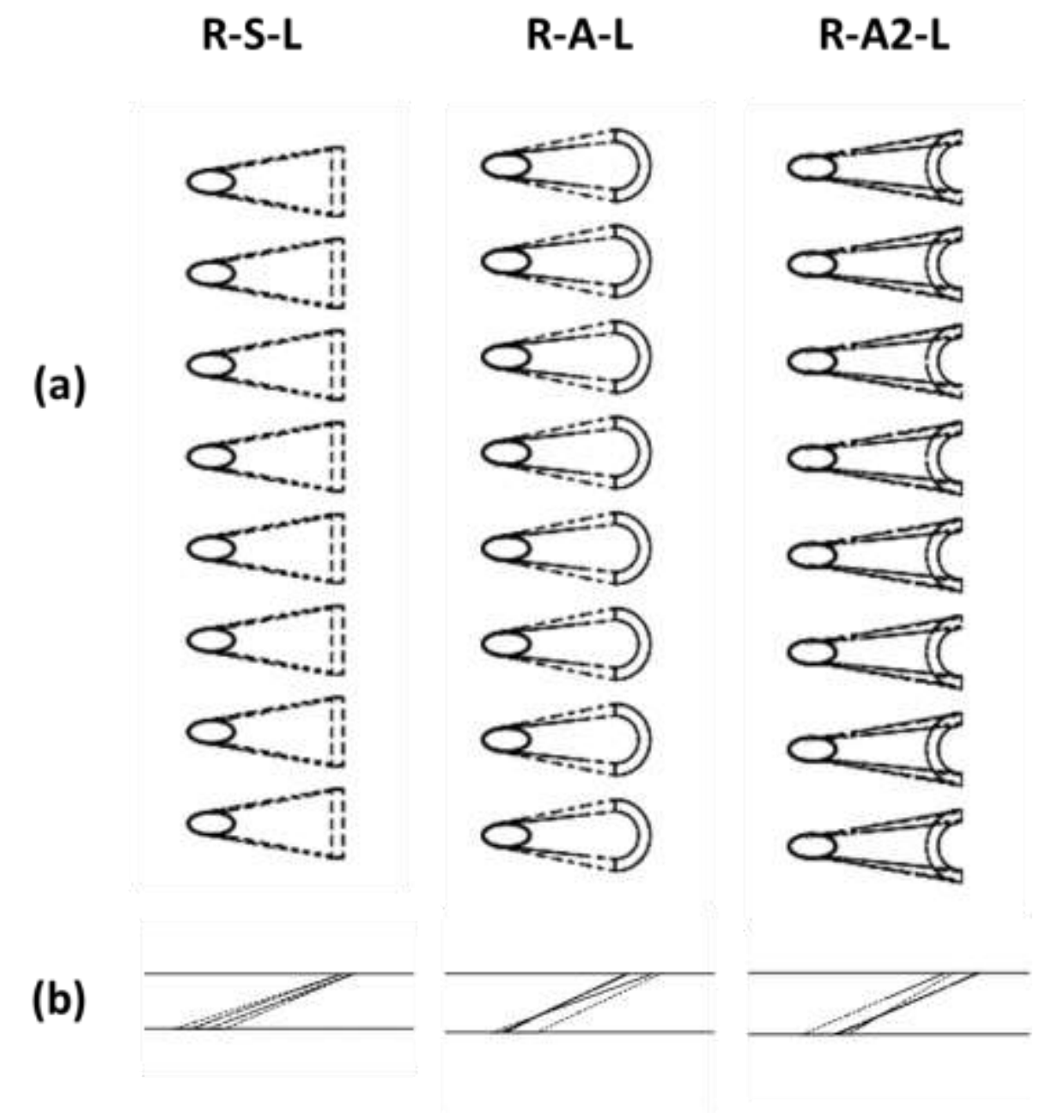

Figure 4: (a) Left to Right: Round to Slot-Linear (R-S-L), Round to AnnulusLinear (R-A-L), Round to Annulus2-Linear (R-A2-L), (b) Cross sectional view showing the linear trajectory profile. 


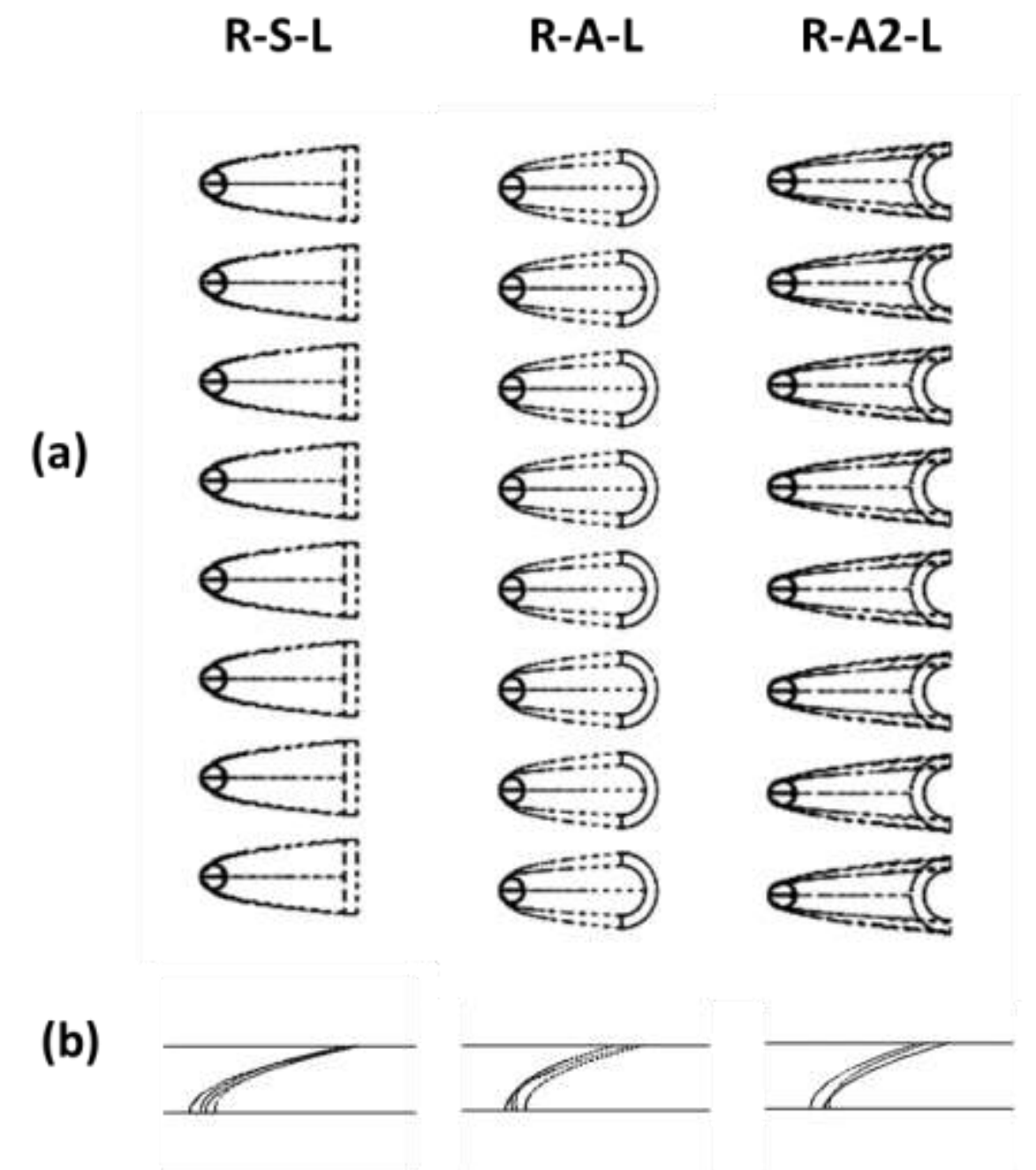

Figure 5: (a) Left to Right: Round to Slot-Projectile (R-S-P), Round to AnnulusProjectile (R-A-P), Round to Annulus2-Projectile (R-A2-P), (b) Cross sectional view showing the projectile trajectory profile. 


\begin{tabular}{|c|c|c|c|c|c|c|}
\hline \multirow[b]{2}{*}{ Parameter/Shape } & \multicolumn{2}{|c|}{ Rectangular } & \multicolumn{2}{|c|}{ Annulus } & \multicolumn{2}{|c|}{ Annulus2 } \\
\hline & $\begin{array}{l}\text { Linear } \\
\text { R-S-L }\end{array}$ & $\begin{array}{l}\text { Projectile } \\
\text { R-S-P }\end{array}$ & $\begin{array}{l}\text { Linear } \\
\text { R-A-L }\end{array}$ & $\begin{array}{l}\text { Projectile } \\
\text { R-A-P }\end{array}$ & $\begin{array}{l}\text { Linear } \\
\text { R-A2-L }\end{array}$ & $\begin{array}{l}\text { Projectile } \\
\text { R-A2-P }\end{array}$ \\
\hline Diameter(mm) & 4 & 4 & 4 & 4 & 4 & 4 \\
\hline$P / d$ & 4 & 4 & 4 & 4 & 4 & 4 \\
\hline Inlet Angle ( $\alpha)$ & $30^{\circ}$ & $30^{\circ}$ & $30^{\circ}$ & $90^{\circ}$ & $90^{\circ}$ & $90^{\circ}$ \\
\hline Exit slot Height(d) & $3 d$ & $3 d$ & $3 d$ & $3 d$ & $3 d$ & $3 d$ \\
\hline Exit slot Width(d) & $(1 / 2) d$ & $(1 / 2) d$ & $(1 / 2) d$ & $(1 / 2) d$ & $(1 / 2) d$ & $(1 / 2) d$ \\
\hline Exit slot to slot Distance(d) & $\mathrm{d}$ & $\bar{d}$ & $d$ & $\bar{d}$ & $\bar{d}$ & $\mathrm{~d}$ \\
\hline $\begin{array}{l}\text { Exit/Inlet Area Ratio } \\
\left(A_{\text {exit }} / A_{\text {inlet }}\right)\end{array}$ & 1.9 & 1.9 & 2.5 & 2.5 & 2.5 & 2.5 \\
\hline
\end{tabular}

Table 2: Design parameters for six test cases

\subsection{Experimental procedure}

Pressure sensitive paint is used to determine the adiabatic cooling effectiveness for each plate. PSP is a well-known mass transfer technique used previously [32]. PSP technique is widely in high speed turbomachinery application and aerospace application for determining the pressure distribution of a surface.

PSP is a photoluminescent material that emits light upon excitation with LED.

The intensity of emitted light depends on partial pressure of oxygen on the surface. The less the partial pressure of oxygen, the more is the intensity of emitted light. The emitted light is ultimately captured using a CCD camera. 
PSP ((Innovative Scientific Solutions Inc., Dayton, OH, UF-750) is excited by using a 400nm LED (Innovative Scientific Solutions, Inc. ISSI LM2X LED array). The emitted light by PSP is captured by a CCD (SensiCam QE, The COOKE Corp) with $640 * 480$ spatial resolution, $600 \mathrm{~nm}$ filter, $12 \mathrm{bit}$ RGB or grey level) camera.

Calibration for the PSP was carried out by painting a small test coupon and placing it inside a vacuum chamber. Figure 6 shows the calibration setup. Chamber is pressurized to $29 \mathrm{inHg}$ using a vacuum pump. Pressure is brought back to $0 \mathrm{inHg}$ by an increment of 4 inHg. At each pressure the intensity is captured by averaging 200 images. Ambient pressure was used as reference pressure $\left(\mathrm{P}_{\text {ref }}\right)$ and intensity measured at this pressure is reference intensity ( $\left.\mathrm{I}_{\text {ref }}\right)$. The emission intensity ( $\left.\mathrm{I}_{\mathrm{blk}}\right)$ at completely black condition (LED off) is also measured and is subtracted from (I) and ( $\left.\mathrm{I}_{\text {ref }}\right)$ to take care for the background noise. The emission intensity (I) and partial pressure of oxygen (P) can thus be correlated by using the power fitting curve shown in Figure 7. It must be noted that already calibrated curved [33] are also used in some of the current test plates. It is worth mentioning that PSP is not sensitive to camera view angle and therefore the data uncertainty due to view angle can be eliminated. 


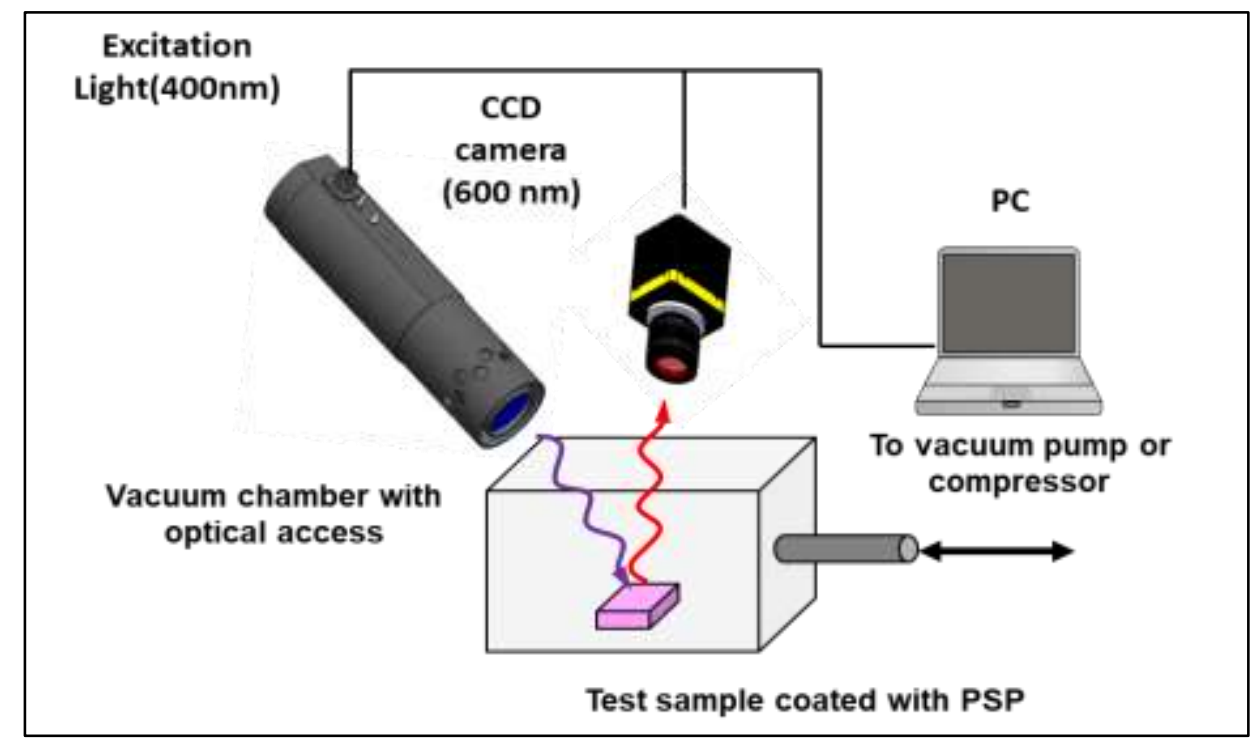

Figure 6: Calibration setup

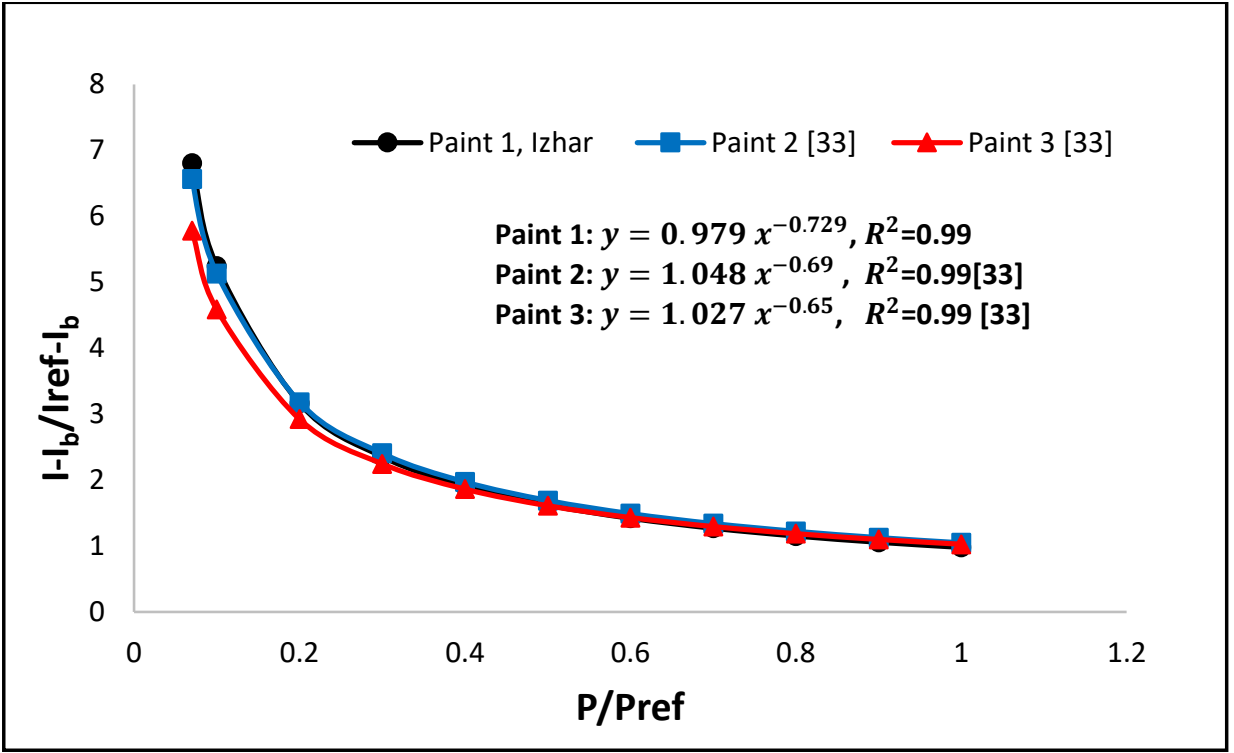

Figure 7: Calibration curve

Generally mass transfer and heat transfer can be analogous if the turbulence Lewis number tends to unity [30]. 
Since PSP is a mass transfer technique, adiabatic film cooling effectiveness is given by,

$\eta=\frac{T_{a w}-T_{m}}{T_{c}-T_{m}} \cong \frac{C_{w}-C_{m}}{C_{c}-C_{m}}=\frac{P_{O_{2}, \text { air }}-P_{O_{2}, f g}}{P_{O_{2}, a i r}}$

Where $\mathrm{C}_{\mathrm{w}}, \mathrm{C}_{\mathrm{c}}$ and $\mathrm{C}_{\mathrm{m}}$ are the concentration of coolant near the wall, coolant concentration and mainstream air concentration respectively.

When density ratio is different from 1.0, the film effectiveness can be found by [33], $\eta=1-\frac{1}{\left(\frac{P_{O_{2}, a i r}}{P_{O_{2}, f g}}-1\right) \times \frac{W_{f g}}{W_{\text {air }}}+1}$

Typically, four tests are carried out to calculate the final film cooling effectiveness: black test, reference test, air test and coolant test. At each test 200 images are captured and averaged out to get the final intensity. The black image intensity ( $\left.\mathrm{I}_{b l k}\right)$ is carried out at completely black condition with no mainstream and no coolant. The reference image intensity $\left(\mathrm{I}_{\text {ref }}\right)$ is captured at condition with no mainstream and no coolant but the LED is turned on. The air image intensity $\left(\mathrm{I}_{\text {air }}\right)$ is captured with the mainstream air on and coolant is injected as air at different blowing ratios. The foreign gas image intensity $\left(\mathrm{I}_{\mathrm{fg}}\right)$ is captured with mainstream on and coolant injected as foreign gas at different blowing ratios. All the intensities are converted to partial pressures using the power fitting curve obtained already to find the final effectiveness.

Discharge coefficient is measured by using the following formula from Burd et al [26]:

$\overline{c_{d}}=\frac{\dot{m}_{c}}{\dot{m}_{i}}$

Where 
$\dot{m}_{i}=A \sqrt{\left(2 \rho_{c}\left(P_{c, T}-P_{s}\right)\right)}$

Actual mass flow rate $\dot{m}_{c}$ is maintained by using dwyer flowmeter. Mainstream static pressure $P_{s}$ is measured using a pitot static tube while the coolant pressure $P_{c, T}$ is measured using pressure tap at the inlet coolant plenum.

\subsection{Experimental uncertainty}

The uncertainty in the measurement is mainly due to uncertainty in calibration and uncertainty in measurement of PSP emission intensity. Using Kline and McClintock [35] approach the uncertainty for $\eta=0.70, \eta=0.38 \& \eta=0.20$ is $2.2 \%, 4.6 \% \& 8.8 \%$ respectively. 


\section{RESULTS \& DISCUSSION}

\subsection{Literature comparison}

Round to slot- Linear trajectory (R-S-L) with aspect ratio $\mathrm{AR}=6$ is taken as a reference case. Data for this plate is compared to An et al [21] which is the most closely related data available in open literature terms of main stream conditions, cooling hole diameter and test method. Variation of data as compared to An's data shown in Figure 8 and Figure 9 might be due to difference in aspect ratio and the configuration (which is slot to slot for Bai as compared to round to slot for the current case). An carried out PSP test on a flat plate with hole diameter $\mathrm{d}=4 \mathrm{~mm}$, Inlet angle $\alpha=30^{\circ}$, Lateral diffusion angle $\Upsilon=14^{\circ}$, Slot to Slot hole configuration with aspect ratio of $A R=5$ and $A R=6.7$ at density ratio of 1.38. Data of R-S-L seems to be in good agreement with the open literature.

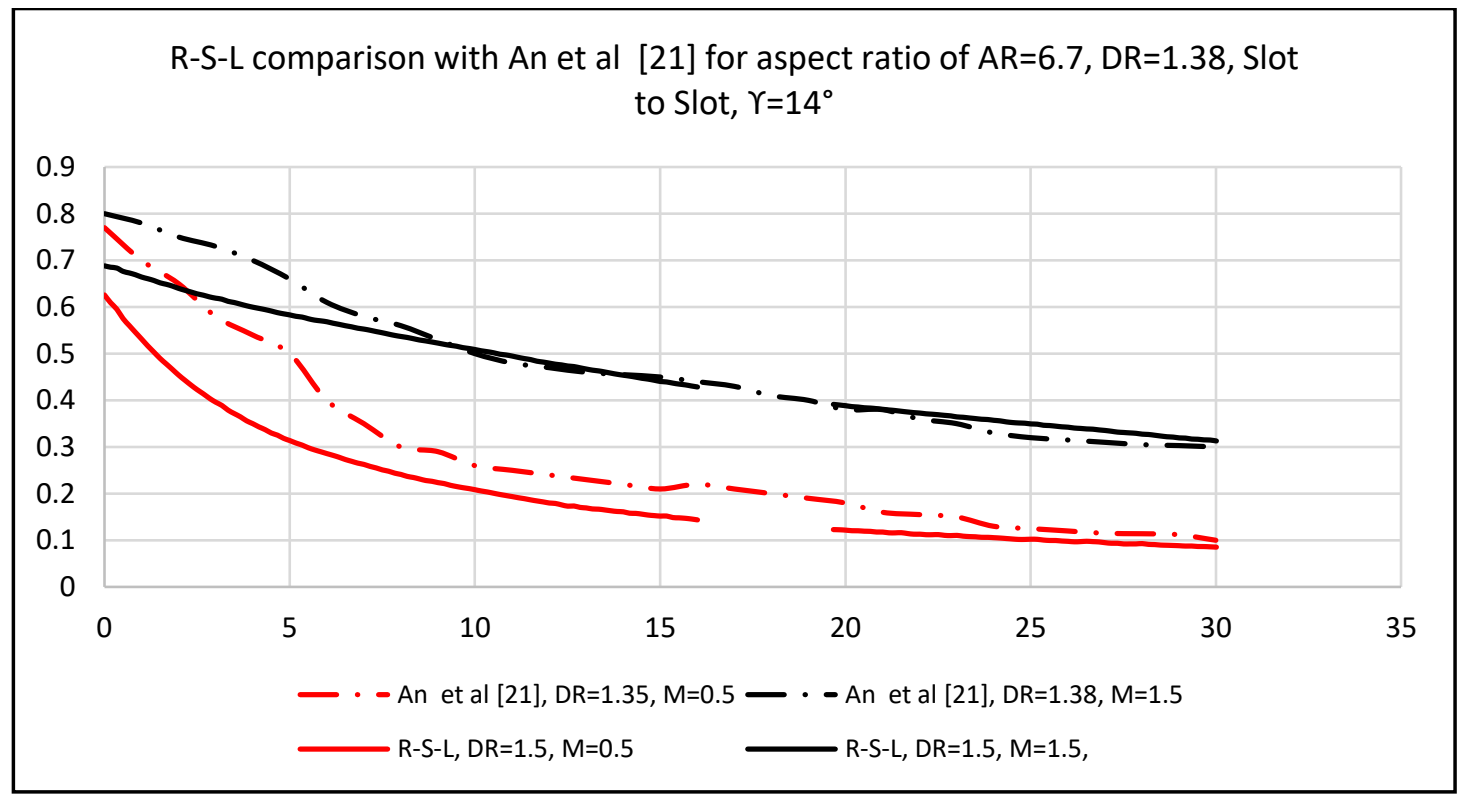

Figure 8: Round to Slot-Linear test plate comparison with open literature ( An et al [21]) 


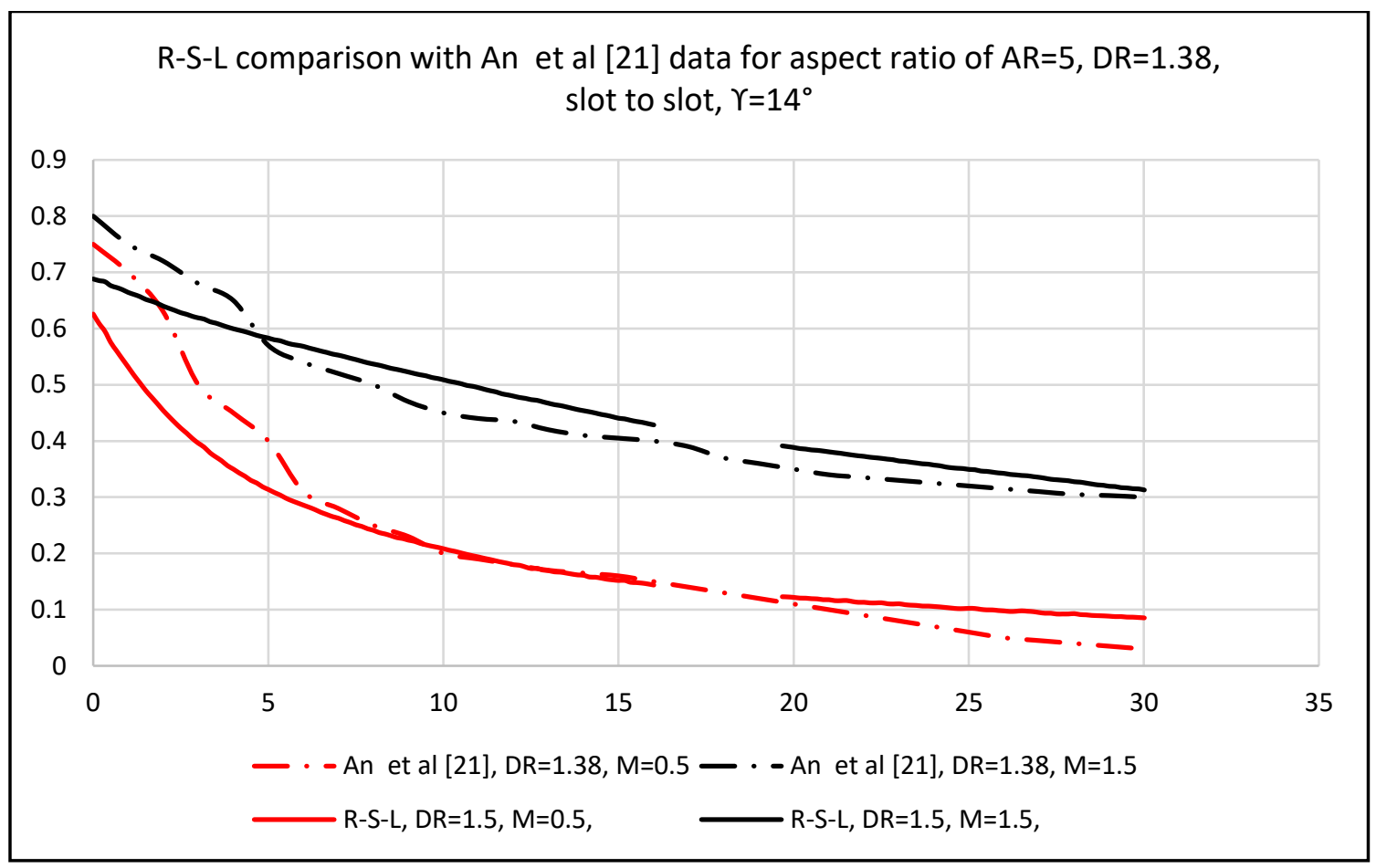

Figure 9: Round to Slot-Linear test plate comparison with open literature ( An et al [21])

\subsection{Blowing ratio effect}

Figure 10, 11\& 12shows the effect of blowing ratio on the film cooling effectiveness for $\mathrm{DR}=1,1.5$ and 2 respectively. Chen et al [32] also studied the effect of blowing ratio on film cooling effectiveness for shaped holes, results suggested that in general for shaped holes the effectiveness is increasing with increase in blowing ratio primarily because of reduced coolant lift off.

Similar results are obtained for the current study. As all the current shapes can be regarded as shaped holes, it can be seen that the film cooling effectiveness increases as the blowing ratio is increased. Film cooling effectiveness data starts from the trailing edge of the hole exit $(\mathrm{x} / \mathrm{d}=0)$. For linear trajectory cases $(\mathrm{R}-\mathrm{S}-\mathrm{L}, \mathrm{R}-\mathrm{A}-\mathrm{L} \& \mathrm{R}-\mathrm{A} 2-\mathrm{L})$, as the 
blowing ratio (M) is increased, the effectiveness increases but the increment increase at each blowing ratio is reduced at higher blowing ratio $(\mathrm{M}=1-1.5)$ which is due to the coolant lift off. This coolant lift-off increases with increase in blowing ratio, though the coolant lift-off is less significant as compared to cylindrical holes and fan shaped holes. Figure 13, 15 and 17 shows the effectiveness contours for all blowing ratios and density ratios for linear trajectory cases. R-S-L and R-A2-L shows single peak films uniformly ejected with the effectiveness starting from as high as $\eta=0.7$ for $\mathrm{DR}=1$ and $\eta=0.8$ for $\mathrm{DR}=2$ at the leading edge of the exit hole. The film cooling effectiveness data for R-S-L and R-A2-L reduces gradually as x/d increases. Figure 19 shows the probable formation of kidney and anti-kidney pair of vortices all the test designs. For R-S-L and R-A2-L the film cooling distribution pattern is a single peak at the centerline. This single peak film formation is explained by formation of weak anti-kidney pair vortices. This anti-kidney pair vortices cancels the kidney vortices pair resulting in a single peak at the centerline [21]. For R-A$\mathrm{L}$, there seems to be strong interaction between the coolant and mainstream flow resulting in coolant lift off and low bi-peak film cooling distribution. This coolant lift-off and bipeak distribution can be attribute again to the formation of kidney vortices and strong antikidney vortices discussed by An et al [21] and Havens et al [31]. R-A-L can be a considered a stretched R-S-L shape resulting in the anti-kidney vortices being shifted to the edges. This anti-kidney vortices pair cancel the kidney vortices at the edge resulting in no coolant lift off at the edges. The centerline of the hole however has significant coolant lift due to the presence of kidney vortices only. R-A2-L on the other hand is considered as a case which is the opposite of R-A-L resulting in anti-kidney pair of 
vortices being shifted to the center. This results in a single peak behavior as that of R-SL.

For Projectile trajectory test plates, it can be seen in Figure $10,11 \& 12$ that the effectiveness has almost the same trend as that of linear trajectory cases i-e effectiveness increases as the blowing ratio is increased. For $\mathrm{R}-\mathrm{S}-\mathrm{P}, \mathrm{DR}=1$ the effectiveness increases with increase in blowing ratio till $M=1$ but for $M>1$ the coolant is wasted which might be due to coolant lift off. For $\mathrm{DR}=1.5$ the behavior is almost the same as that at $\mathrm{DR}=1$ for $\mathrm{R}$ S-P, R-A-P \& R-A2-P but for DR=2 we see that effectiveness increases continuously with increase in blowing ratio for all shapes unlike $\mathrm{DR}=1.5$ and $\mathrm{DR}=1$ where $\mathrm{R}-\mathrm{S}-\mathrm{P}$ had lift off for $M>1$, in this case due to less volume flow rate for $M>1$ for R-S-P we don't have coolant lift off. Figure 14, 16 and 18 shows the contours for the projectile trajectory test plates. Contours of R-S-P is of significant importance, we see that the coolant is covering almost the complete downstream region especially for $\mathrm{DR}=1.5$ and $\mathrm{DR}=2$ unlike $\mathrm{R}-\mathrm{S}-\mathrm{L}, \mathrm{R}-\mathrm{A}-\mathrm{L}$ \& R-A2-L. R-S-P contours shows tri-peak behavior and the film fully covers the upstream as well as the downstream plates. This tri-peak behavior can be attributed to formation of weak anti-kidney vortices but in a pair of three resulting in tri-peak behavior and less coolant lift-off. These pair of vortices can be seen in Figure 19. For R-S-P the coolant is mostly attached to the surface. In addition to the mainstream and coolant interaction, the projectile shaped trajectory also tends to keep the coolant attached to the surface. R-A-P has poor performance as the increase in effectiveness with increase in blowing ratio is insignificant. Again, for R-A-P due to the exit hole shape the subsequent interaction between mainstream and coolant, we see undesirable contours and coolant lift off. In 
addition, we can see small four peaks film just at the downstream of the exit hole for RA-P which can be due to four pairs of kidney and anti-kidney vortices formed just at the downstream as shown in Figure 19. R-A2-P contours are similar as R-S-P as it also has tri-peak behavior but the film coverage is not as good as R-S-P especially at the centerline between the hole. Film exiting the hole for R-A2-P doesn't merge and make a continuous film like R-S-P in which case both the film merge and provides better coverage. R-A2-P contours are also comparable with R-S-L and R-A2-L except that both the latter geometries have single peaks in their film contours. 


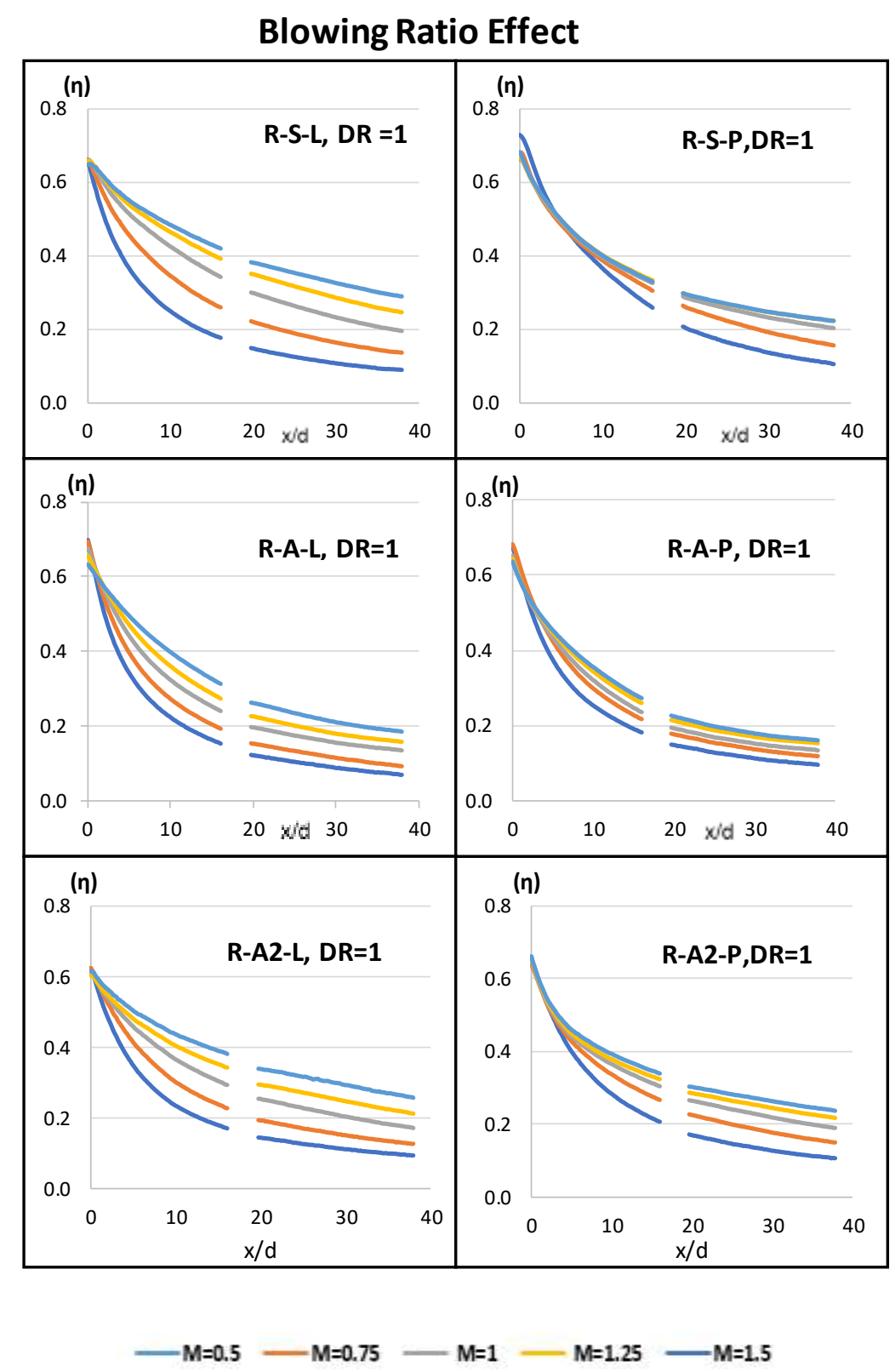

Figure 10: Film cooling effectiveness data for all the shapes for $D R=1$ 


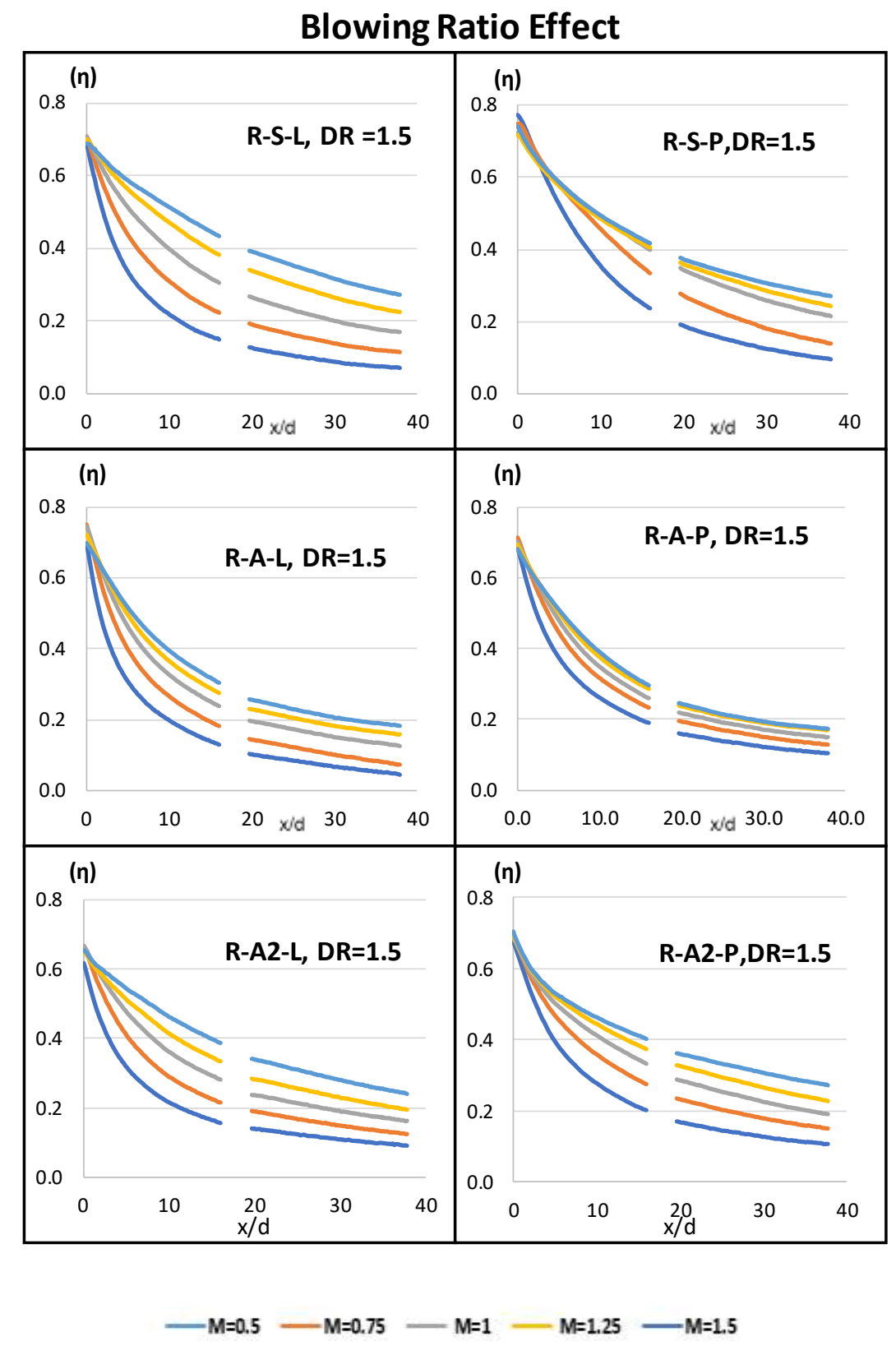

Figure 11: Film cooling effectiveness data for all the shapes for $D R=1.5$ 


\section{Blowing Ratio Effect}

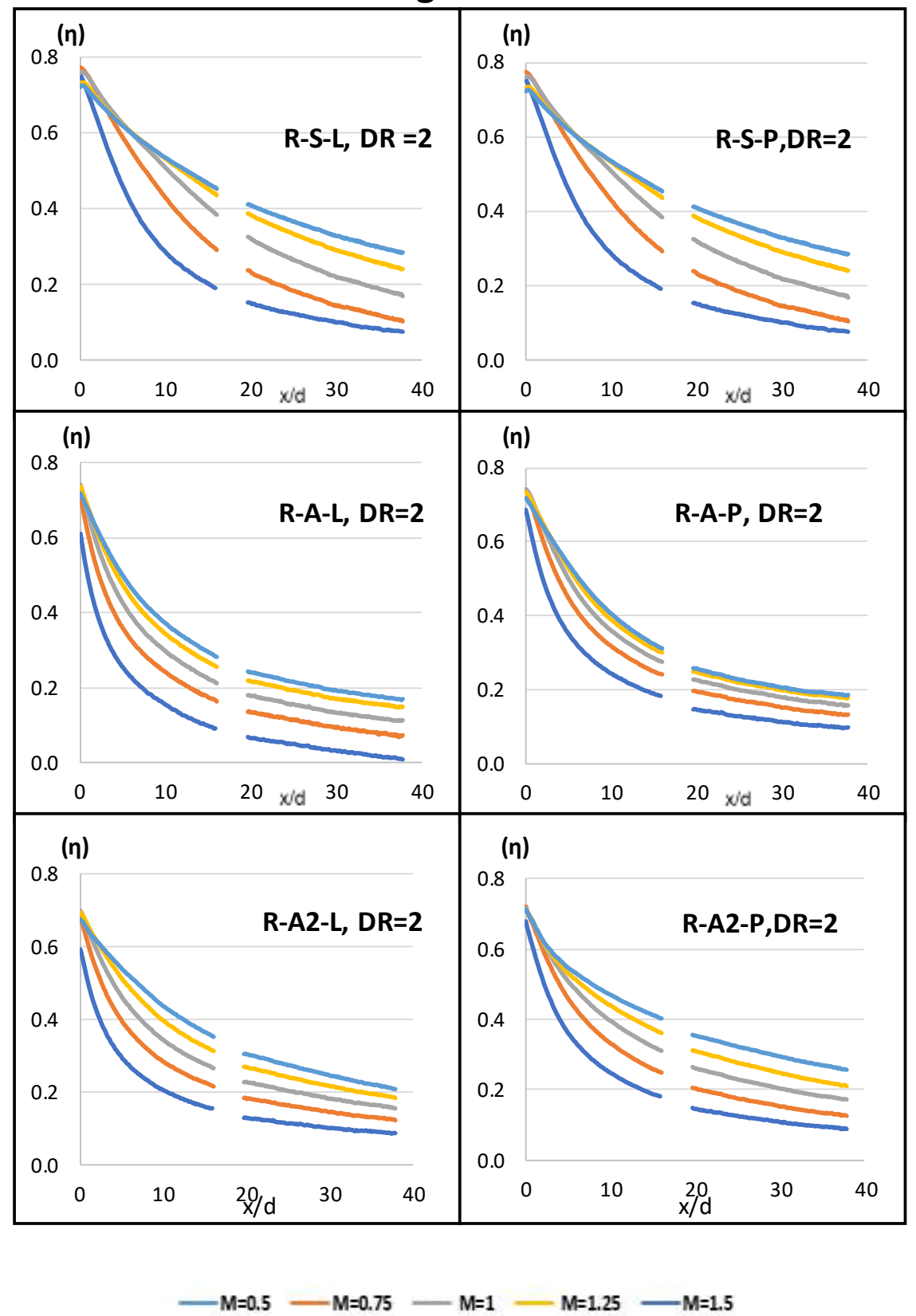

Figure 12: Film cooling effectiveness data for all the shapes for $D R=2$ 


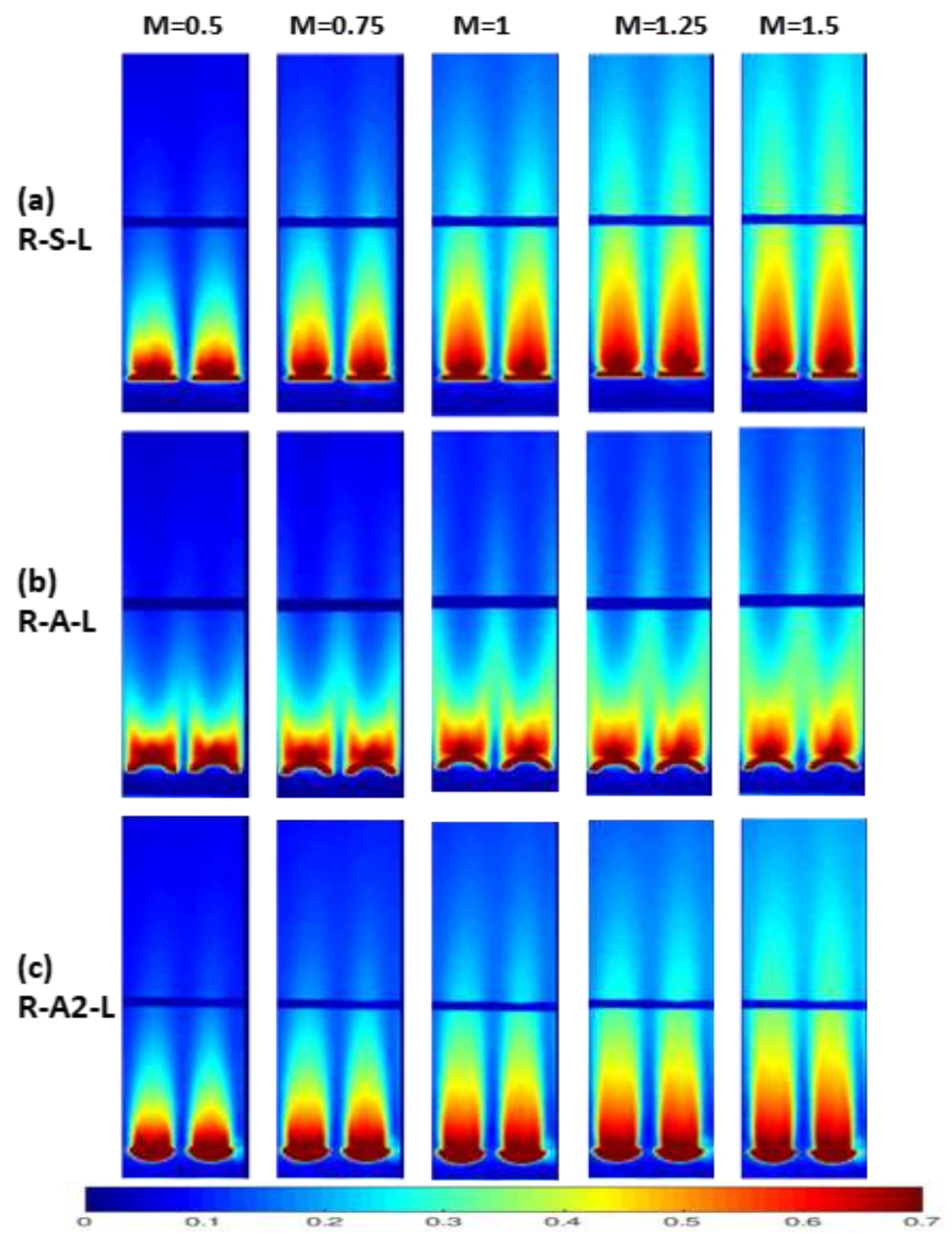

Figure 13:Film cooling effectiveness contours for linear trajectory hole design at $\mathrm{DR}=1$ 


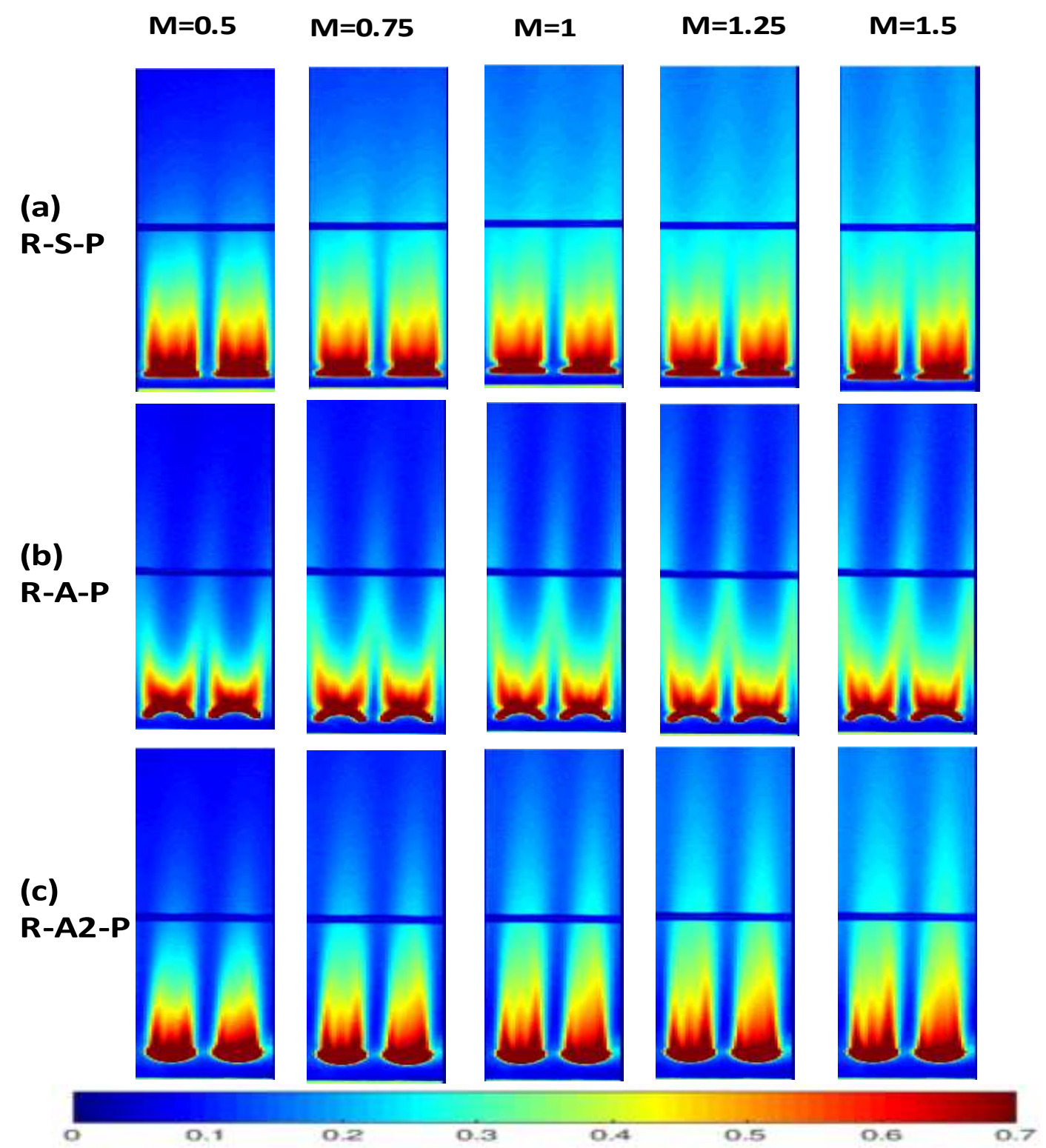

Figure 14: Film cooling effectiveness contours for projectile trajectory contours at $\mathrm{DR}=1$ 


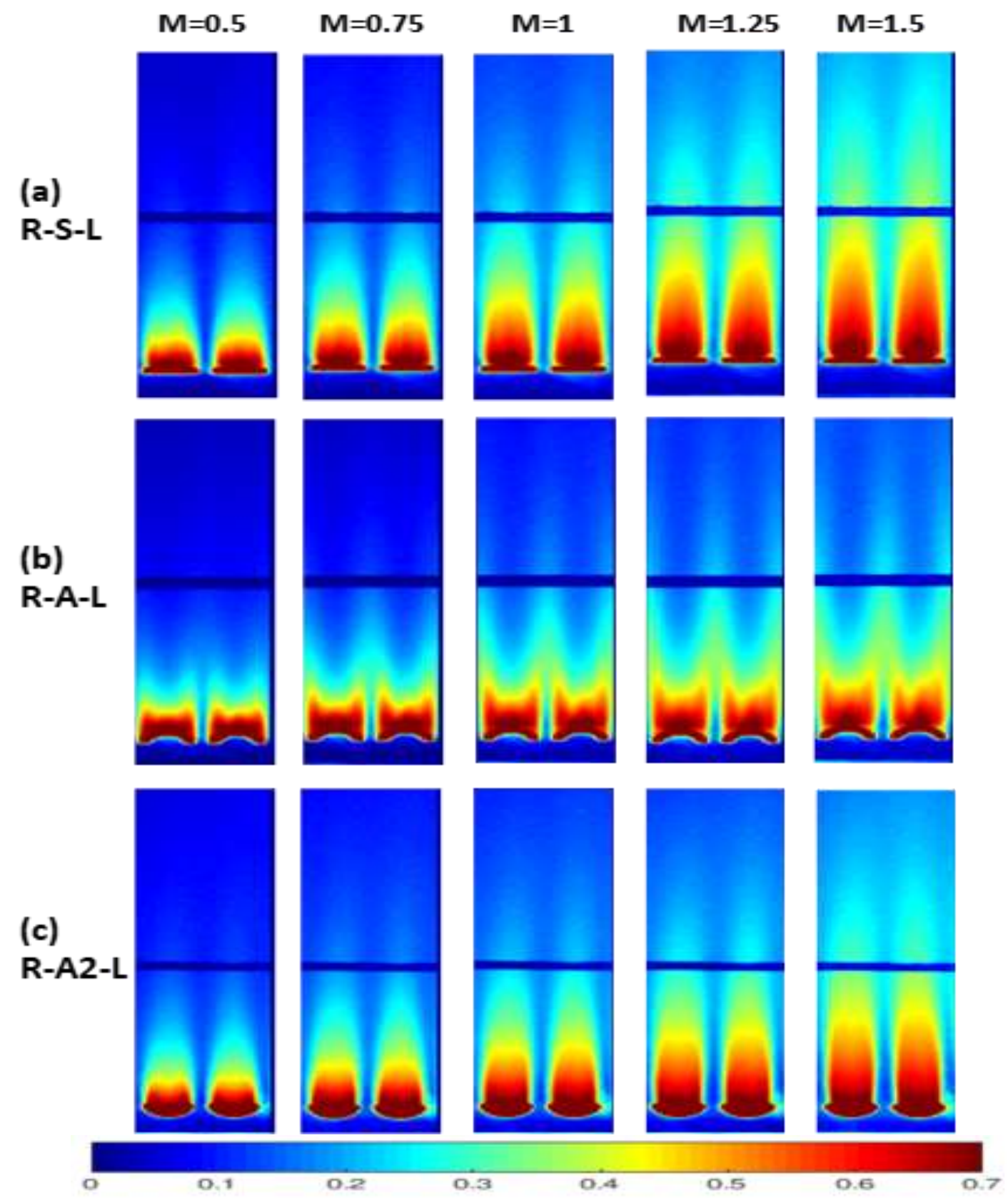

Figure 15:Film cooling effectiveness contours for linear trajectory contours at DR=1.5 


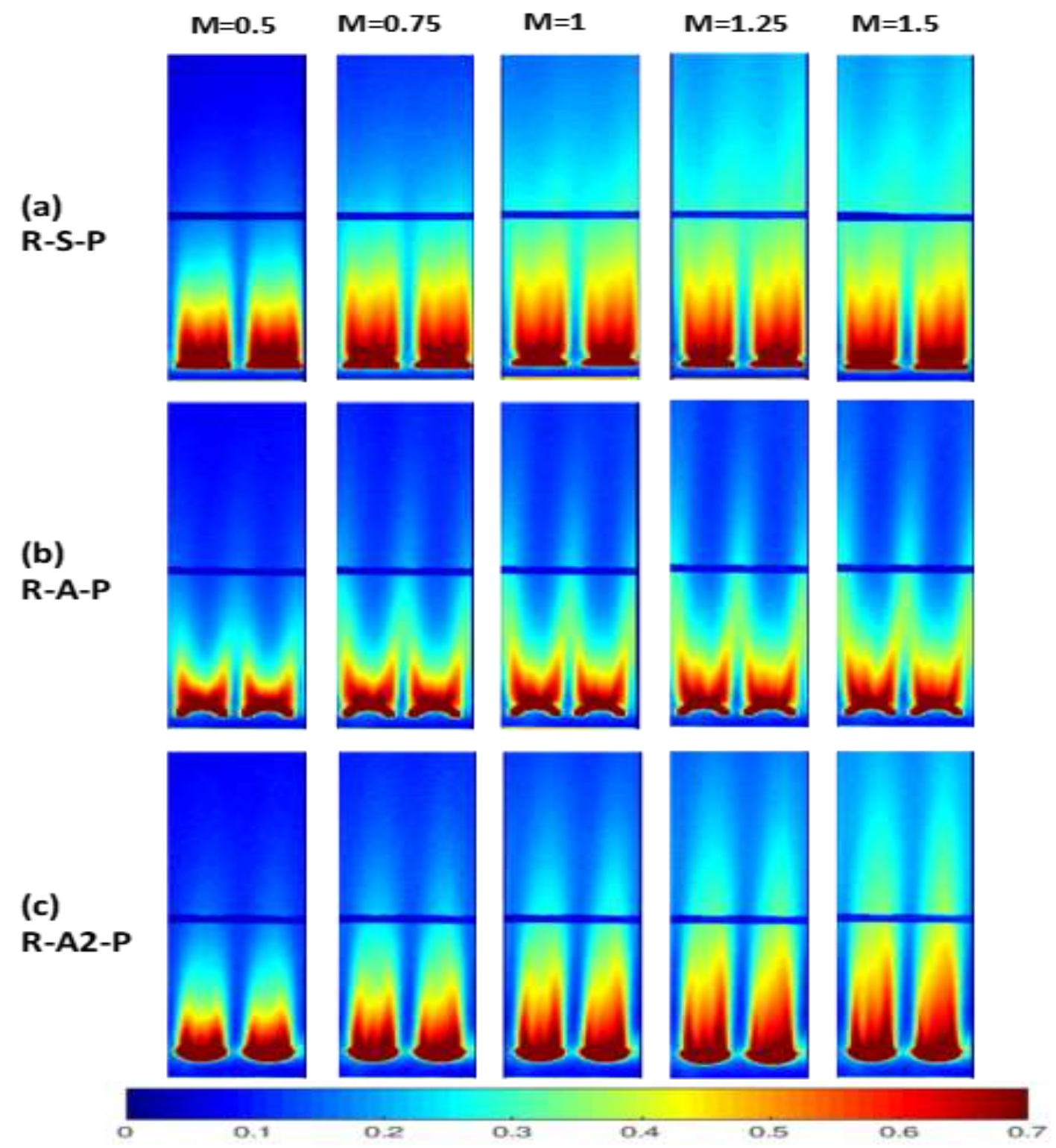

Figure 16:Film cooling effectiveness contours for projectile trajectory contours at $\mathrm{DR}=1.5$ 


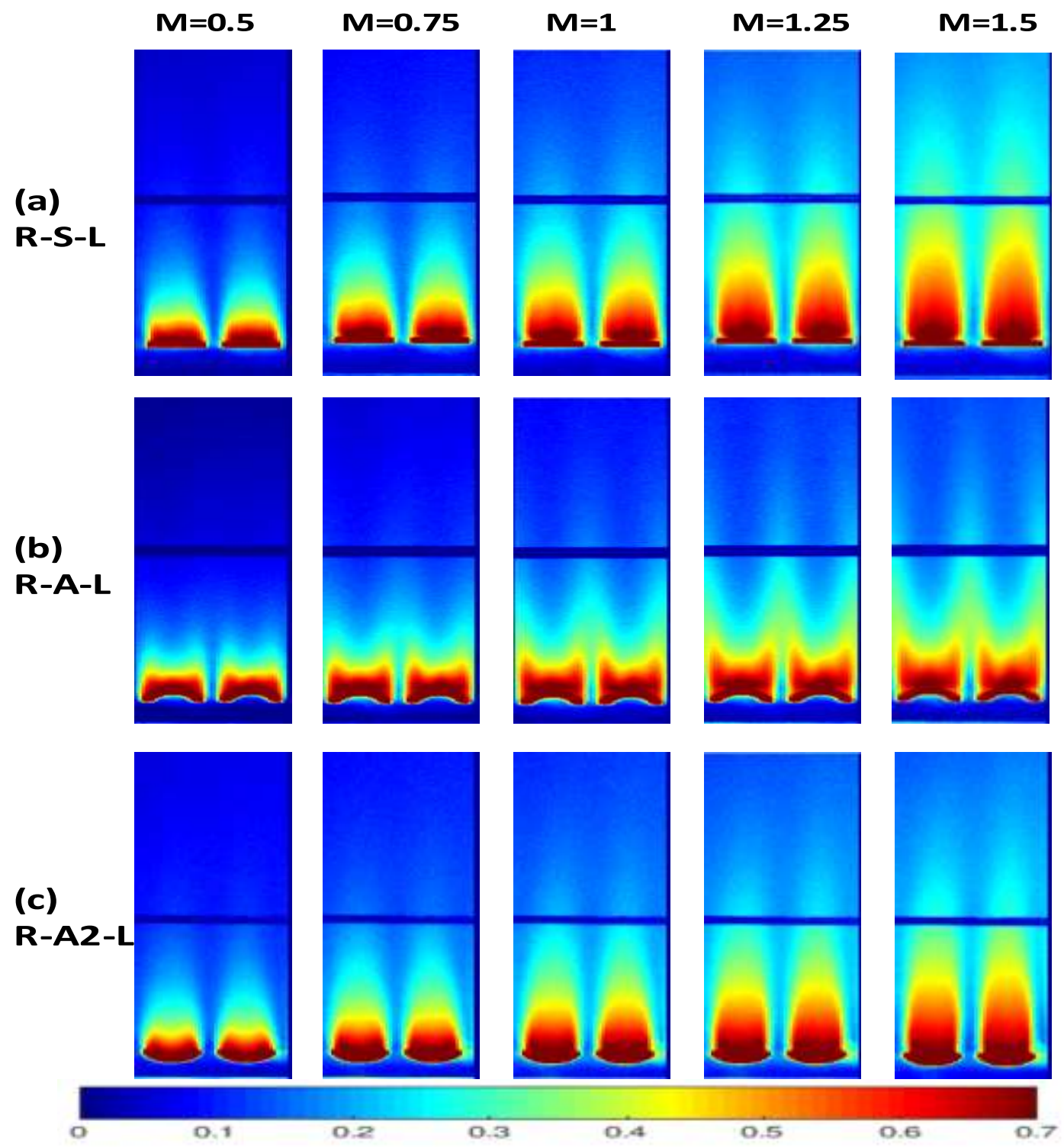

Figure 17:Film cooling effectiveness contours for linear trajectory contours at $\mathbf{D R}=2$ 


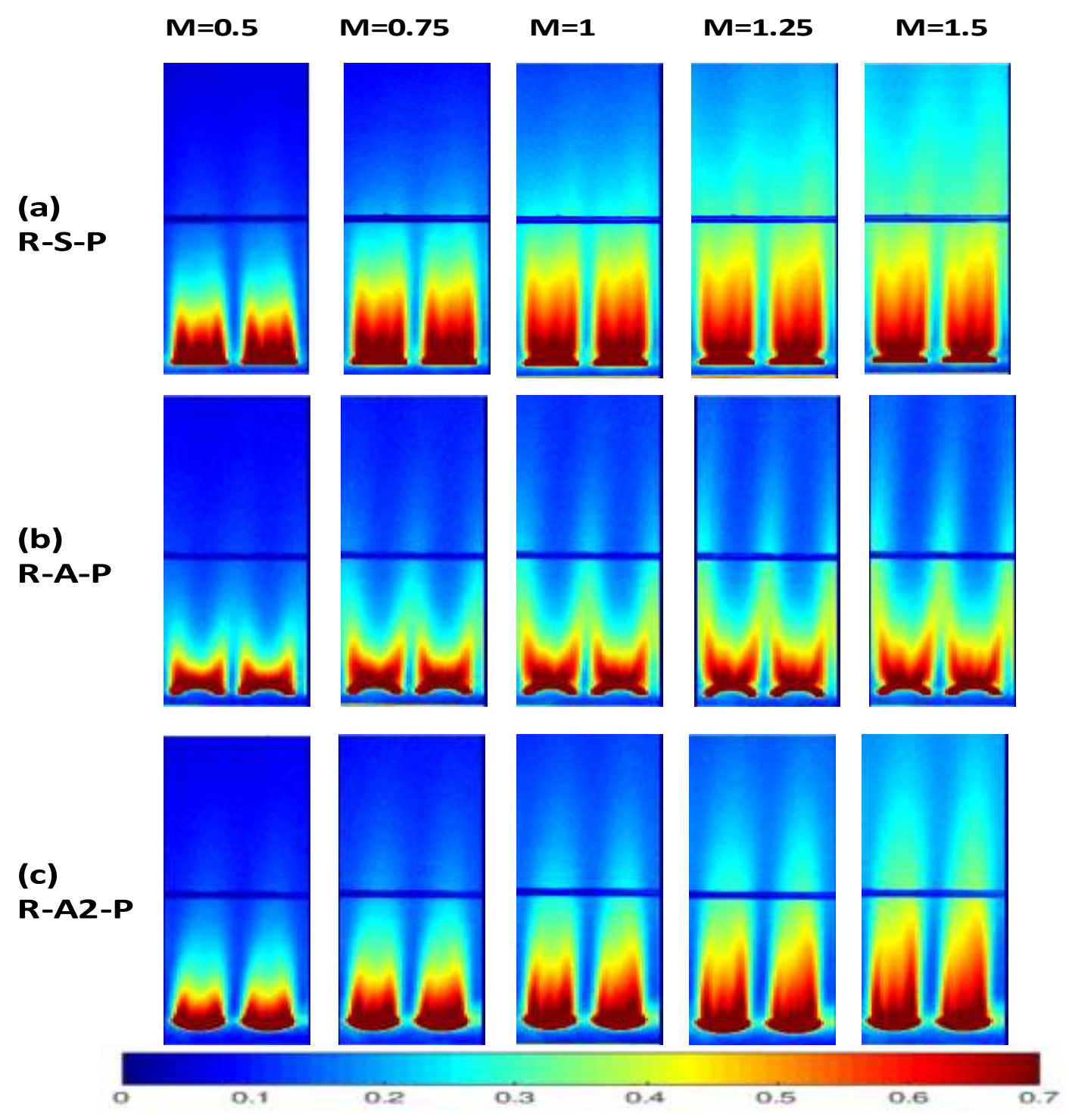

Figure 18:Film cooling effectiveness contours for projectile trajectory contours at $\mathrm{DR}=2$ 


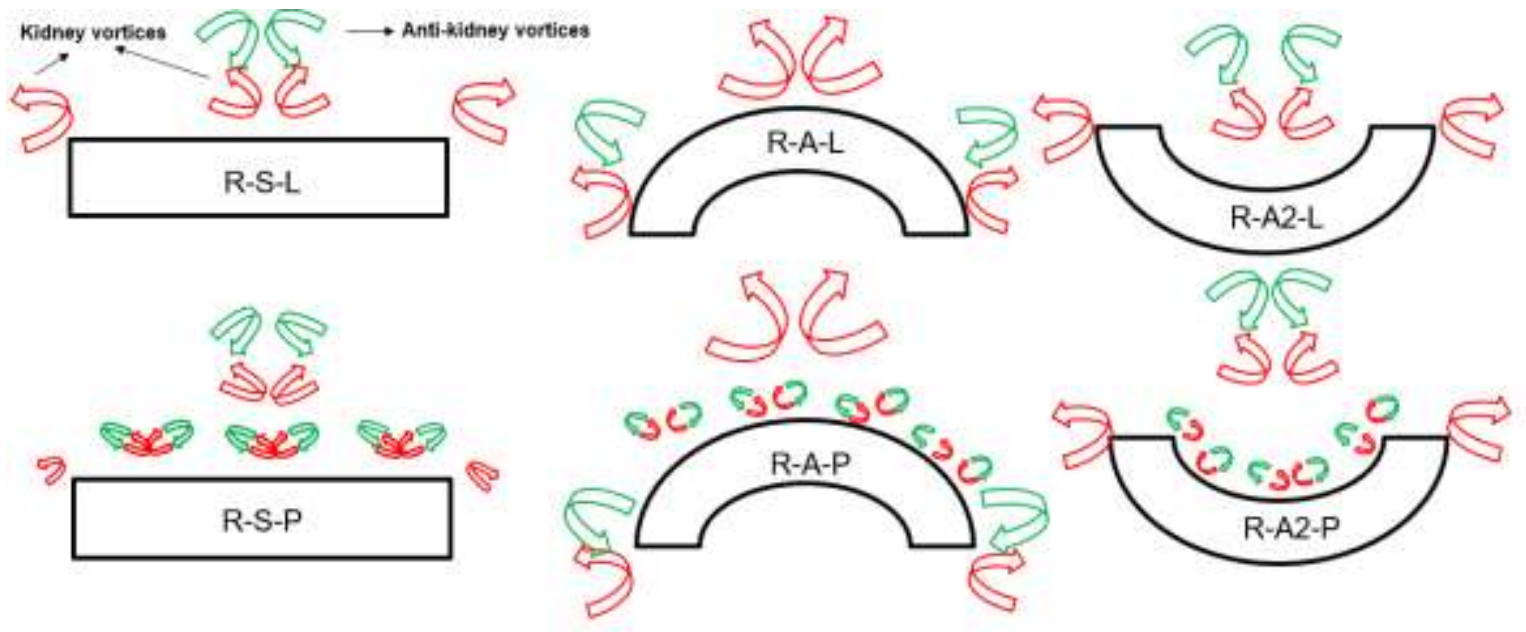

Figure 19: Formation of kidney and anti-kidney vortices for all the shapes. 


\subsection{Density ratio effect}

Density ratio effect of R-S-L and R-S-P has been presented in Figure 19 and Figure 20. Density ratio effect for R-A-L, R-A2-L, R-A-P and R-A2-P are presented in Figure $21,22,23$ and 24 respectively. All the linear trajectory and projectile trajectory test plates has the same trend as R-S-L and R-S-P respectively. For linear trajectory profiles (R-S-L, R-A-L \& R-A2-L) in Figure 19, 21 and 22, for $M \leq 1$, DR has a negative effect of the overall average film cooling effectiveness. The reason could be less volume flow rate and insufficient momentum of coolant at $\mathrm{DR}=1.5$ and 2 as compared to $\mathrm{DR}=1$ resulting in reduced coverage of the coolant. For $\mathrm{M}>1$ the effectiveness is almost the same for $\mathrm{DR}=1.5$ as compared to $\mathrm{DR}=1$ while for $\mathrm{DR}=2$ the effectiveness is less as compared to $\mathrm{DR}=1$. Reason for this might be that $\mathrm{DR}=1.5$ has more coolant attached to the surface than $\mathrm{DR}=1$ where the coolant lifts off partially because of less momentum. However, for DR=2 the coolant remains attached to the surface but the coolant momentum is not sufficient enough (due to less volume of coolant) to increase the effectiveness as compared to $\mathrm{DR}=1.5$, thus resulting in reduction of the average effectiveness. It can be concluded for linear trajectory in general that we have a negative or no impact with the increase in density ratios.

For R-S-P, R-A-P and R-A2-P as presented in Figure 20,23 and Figure 24, we can see that for M=0.5 DR has a negative impact on the film cooling effectiveness due to insufficient momentum of coolant at high density ratios. As the blowing ratio is increased we see that the effectiveness starts to increase. At $\mathrm{M}=0.75$ and $\mathrm{M}=1, \mathrm{DR}=1.5$ and $\mathrm{DR}=2$ has high effectiveness values from $\mathrm{x} / \mathrm{d}=0$ to $\mathrm{x} / \mathrm{d}=15$ due to more coolant attached to the 
surface. However, as $\mathrm{x} / \mathrm{d}$ increases further the effect becomes negligible. For $\mathrm{M}>1$ a positive impact is witnessed for higher DR. An increase in effectiveness of about of 15$20 \%$ is observed at $\mathrm{DR}=1.5$ and $\mathrm{DR}=2$ as compared to $\mathrm{DR}=1$ for $\mathrm{R}-\mathrm{S}-\mathrm{P}$ design.

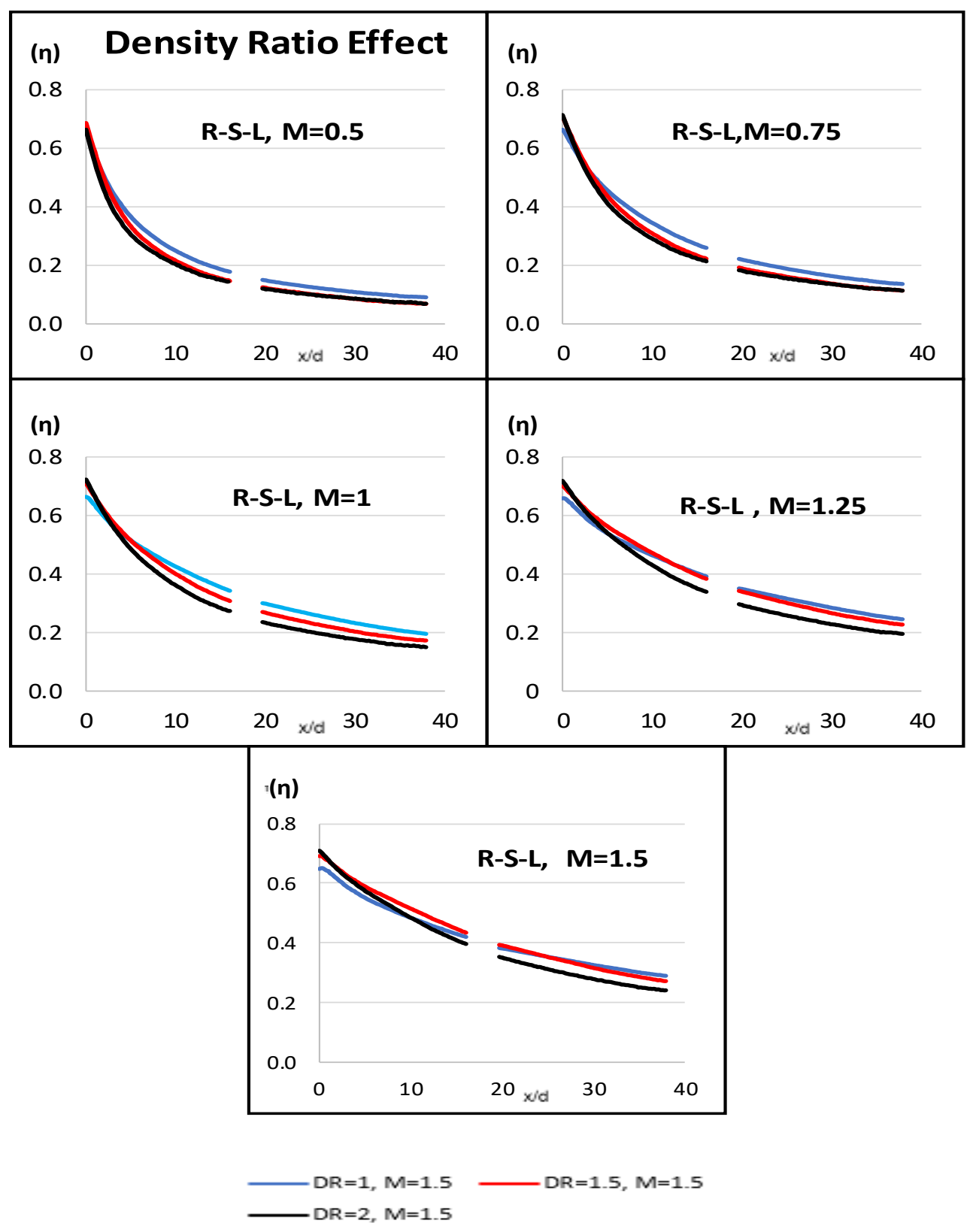

Figure 20: Density ratio effect on span wise film cooling effectiveness for R-S-L 


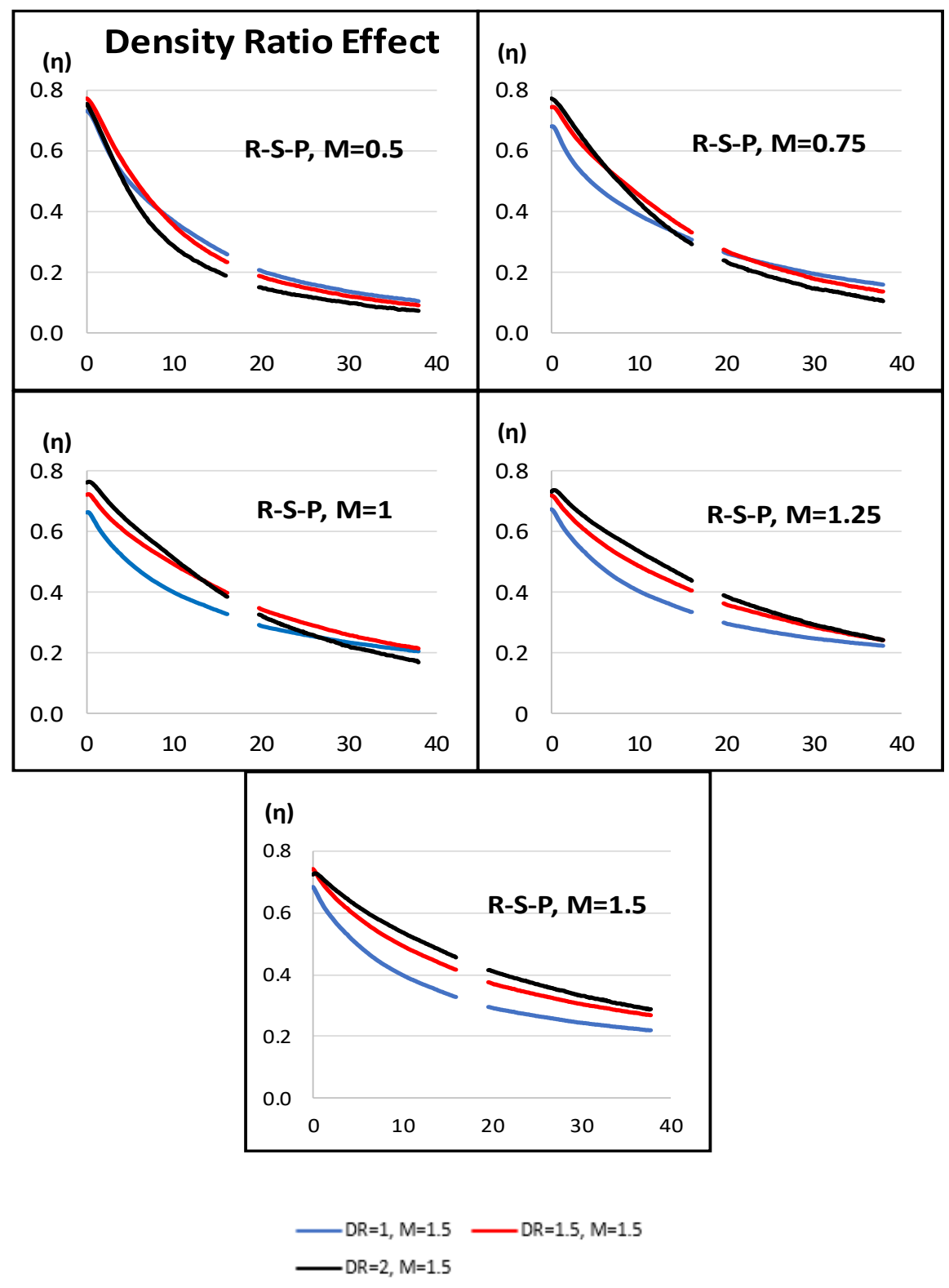

Figure 21:Density ratio effect on span wise film cooling effectiveness for R-S-P 


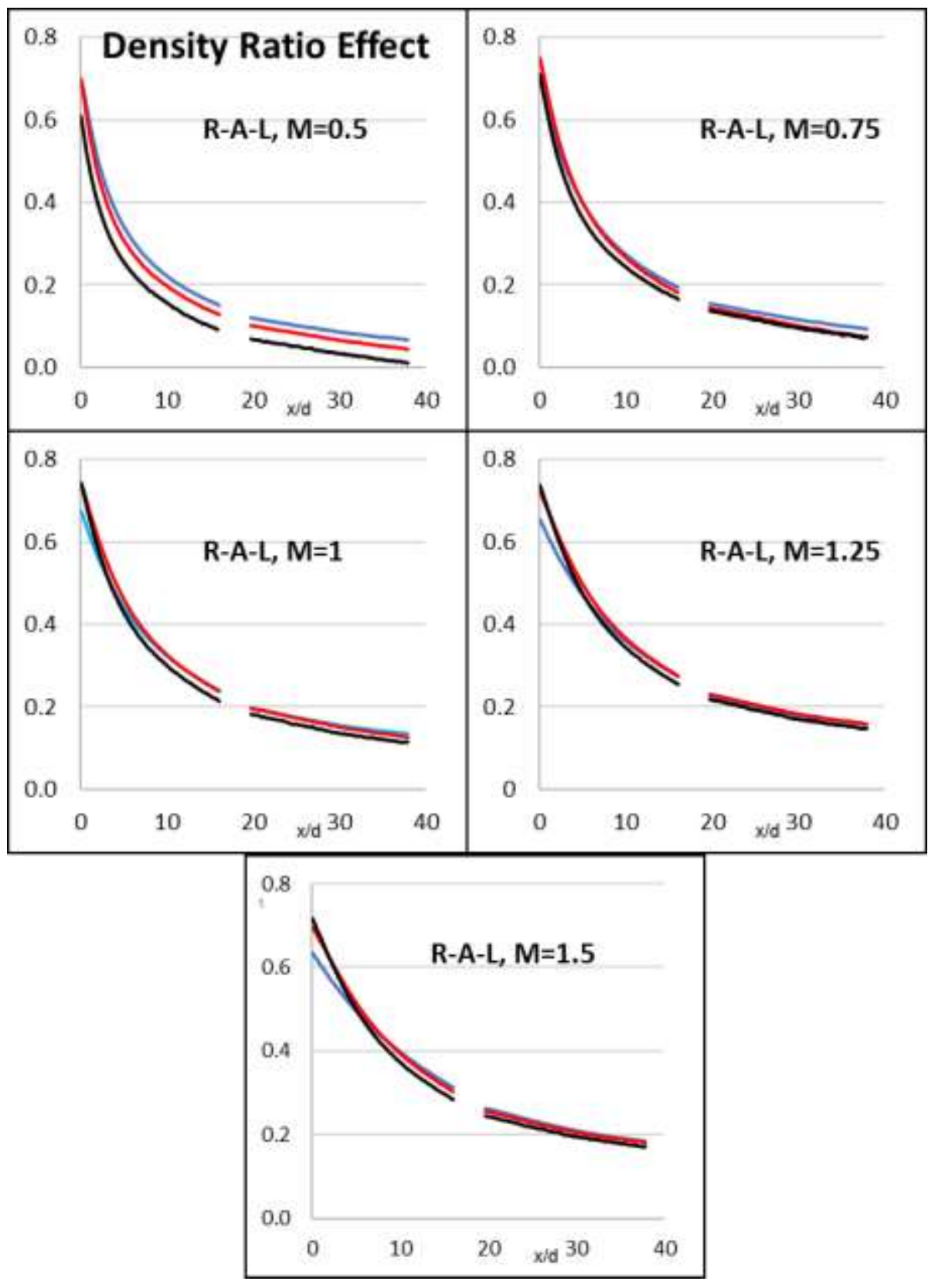

- $D R=1, M=1.5-D R=1.5, M=1.5$

- DR=2, $M=1.5$

Figure 22: Density ratio effect on span wise film cooling effectiveness for R-A-L 


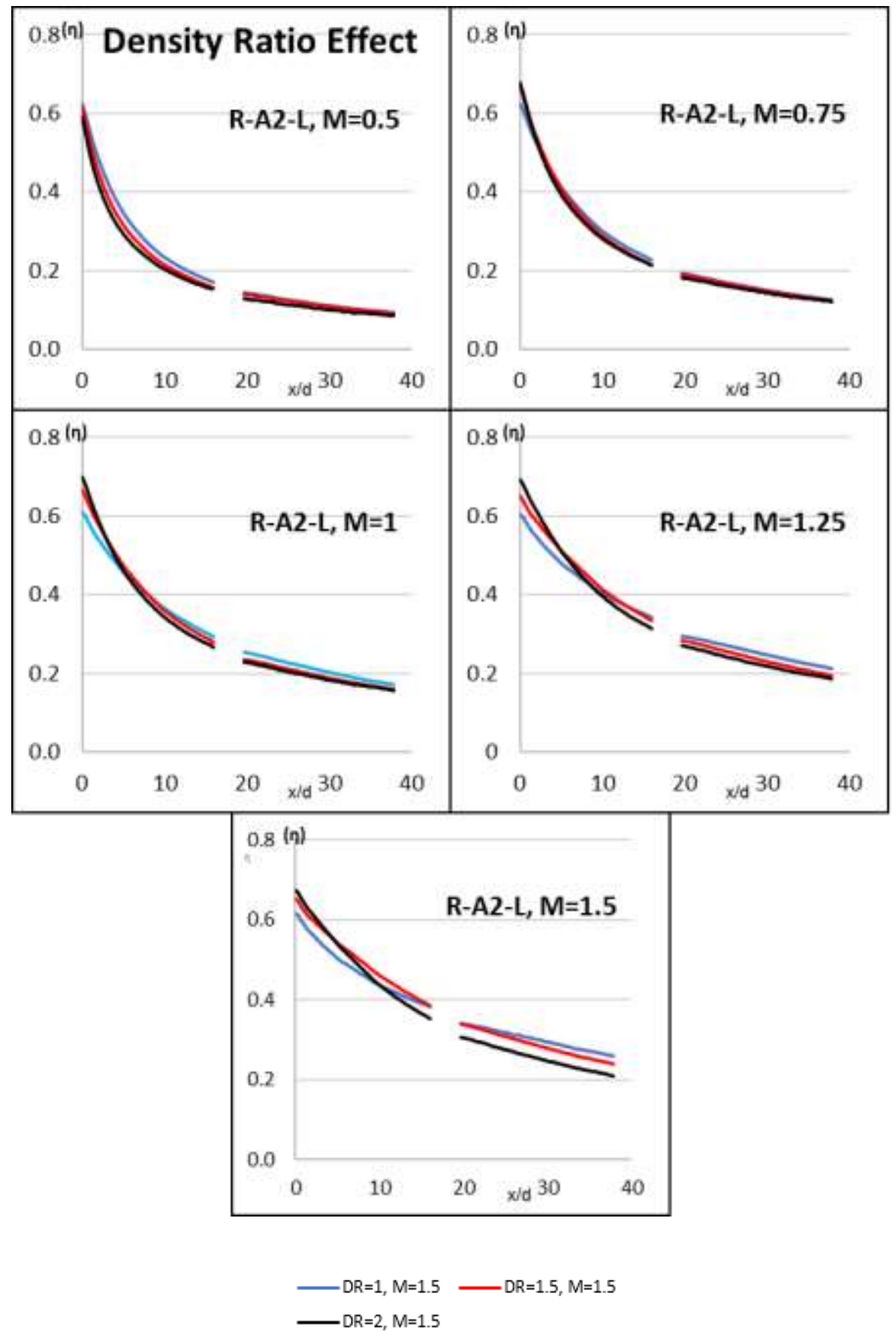

Figure 23: Density ratio effect on span wise film cooling effectiveness for R-A2-L 


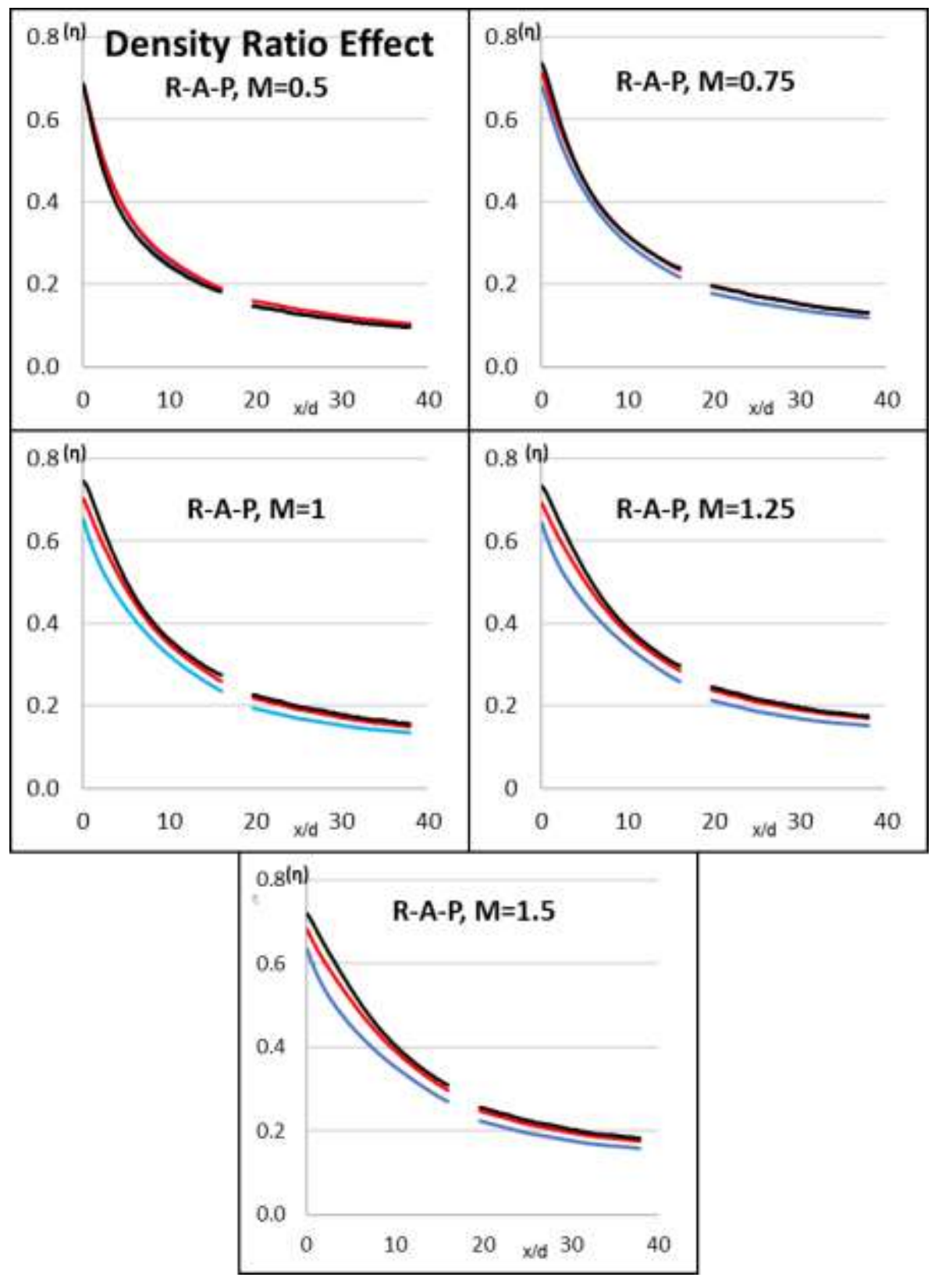

DR=1, $M=1.5 \longrightarrow D R=1.5, M=1.5$

$-\mathrm{DR}=2, \mathrm{M}=1.5$

Figure 24: Density ratio effect on span wise film cooling effectiveness for R-A-P 


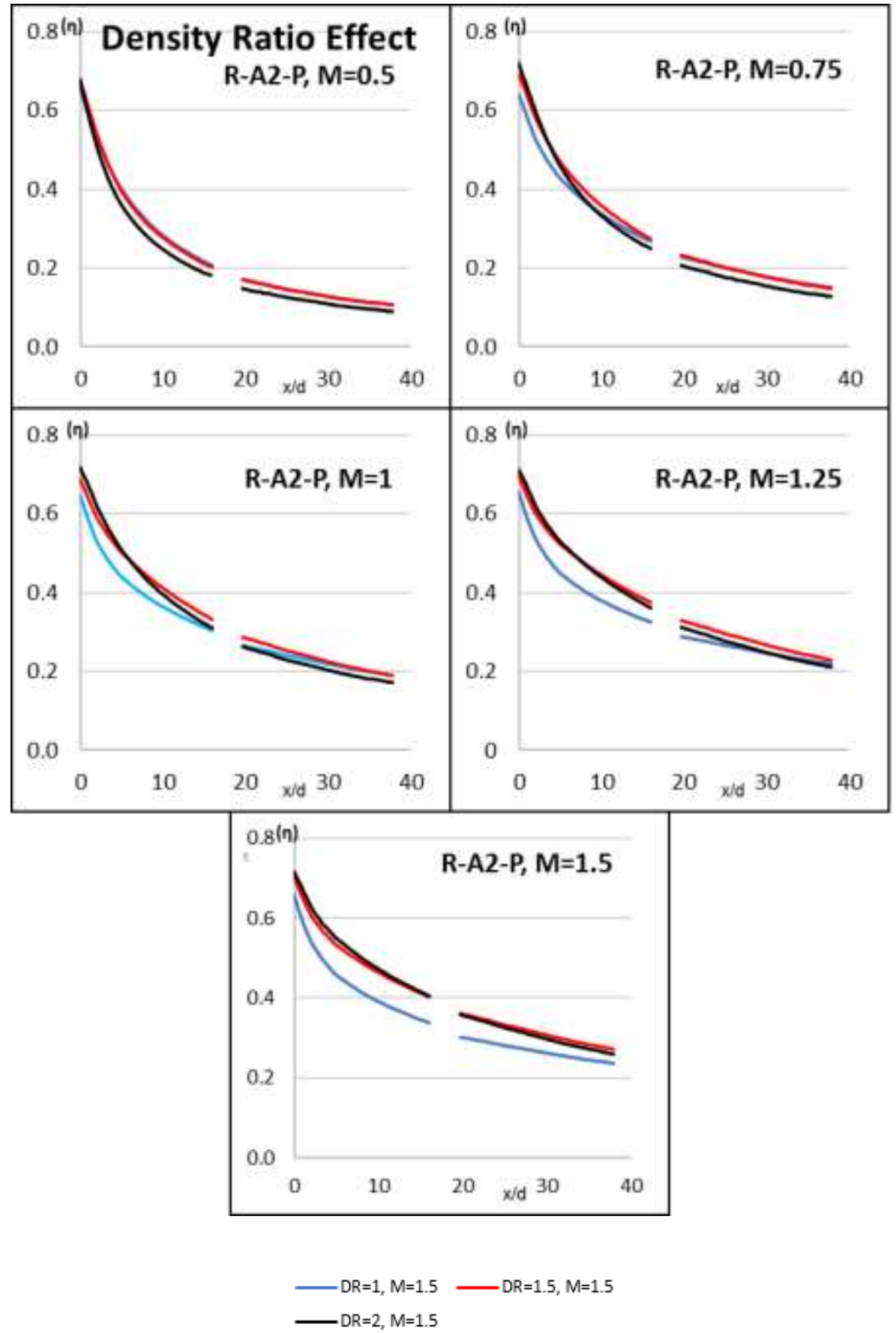

Figure 25: Density ratio effect on span wise film cooling effectiveness for R-A2-P 


\subsection{Exit hole shape and coolant trajectory effect on film effectiveness}

Figure $25,26 \& 27$ represents the span wise data for all the shapes at $\mathrm{DR}=1,1.5$ and $\mathrm{DR}=2$ respectively. It is very clear from the data that $\mathrm{R}-\mathrm{A}-\mathrm{L} \& \mathrm{R}-\mathrm{A}-\mathrm{P}$ are the worst cases resulting in the lowest span wise effectiveness although the effectiveness starts from as high as 0.7 but drops very quickly as we go further downstream. If only comparison is based on the shape of the exit hole then exit hole shape of slot are the best cases (R-S-L \& R-S-P) with highest effectiveness. The exit shape Annulus2 (R-A2-L \& R-A2-P) also acts similar to slot shape giving almost the same effectiveness curve as that of slot case for both the trajectory. The actual difference is made by the trajectory. We can see the RS-P \& R-A2-P has significant amount in increase in its span wise effectiveness as compared to R-S-L \& R-A2-L respectively. However, R-A-P has no significant increase in its effectiveness as compared to R-A-L, the reason for this might be the formation of strong kidney vortices as was the case in R-A-L. R-S-P has almost 20-30\% increase in effectiveness at $\mathrm{M}=0.5-\mathrm{M}=1$ at $\mathrm{DR}=1$. However as discussed earlier at $\mathrm{M}>1$ for $\mathrm{DR}=1$ due to coolant lift off R-S-P effectiveness doesn't increase; therefore R-S-L is more desirable at high blowing ratios and lower density ratios. As we know that DR has a positive impact for a projectile trajectory cases especially at high blowing ratios so we can see R-S-P has an improvement of effectiveness to about $35 \%$ as compared to R-S-L for $\mathrm{M}=0.5$ to $\mathrm{M}=1$ at $\mathrm{DR}=1.5$ but for $\mathrm{M}=1.25$ and $\mathrm{M}=1.5$ the effectiveness is almost the same as that of R-S-L. For DR=2 R-S-P has improved effectiveness of around 20-30\% at all the 
blowing ratios. It is worth mentioning that the real engine conditions are $\mathrm{DR}=1.7-2$, so using a R-S-P design at real engine conditions can be a good way to improve effectiveness.

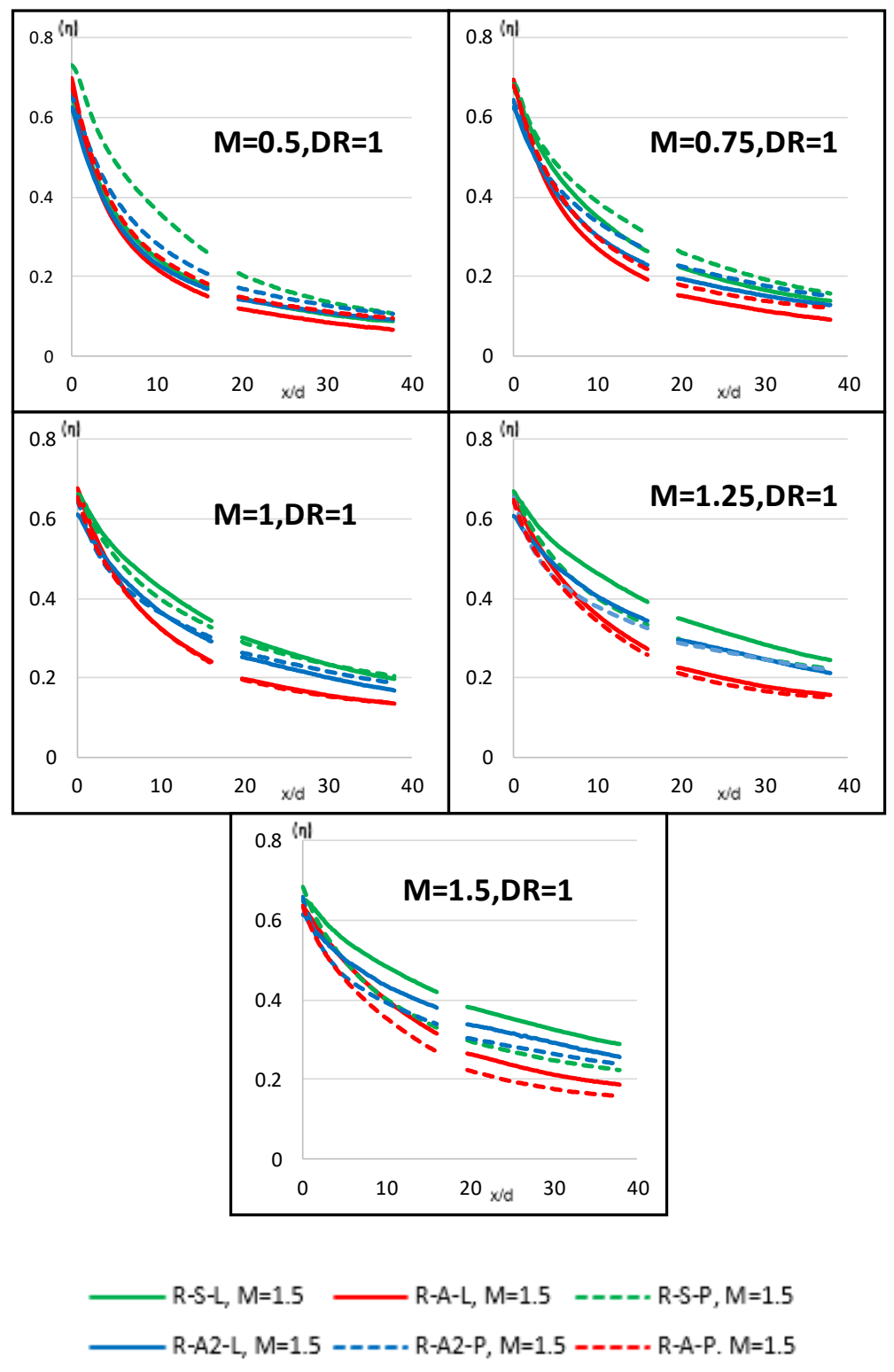

Figure 26:Effect of exit hole shape and the coolant trajectory on film cooling effectiveness for $D R=1$ 
Exit Hole Shape \& Trajectory Effect on Film Cooling Effectiveness

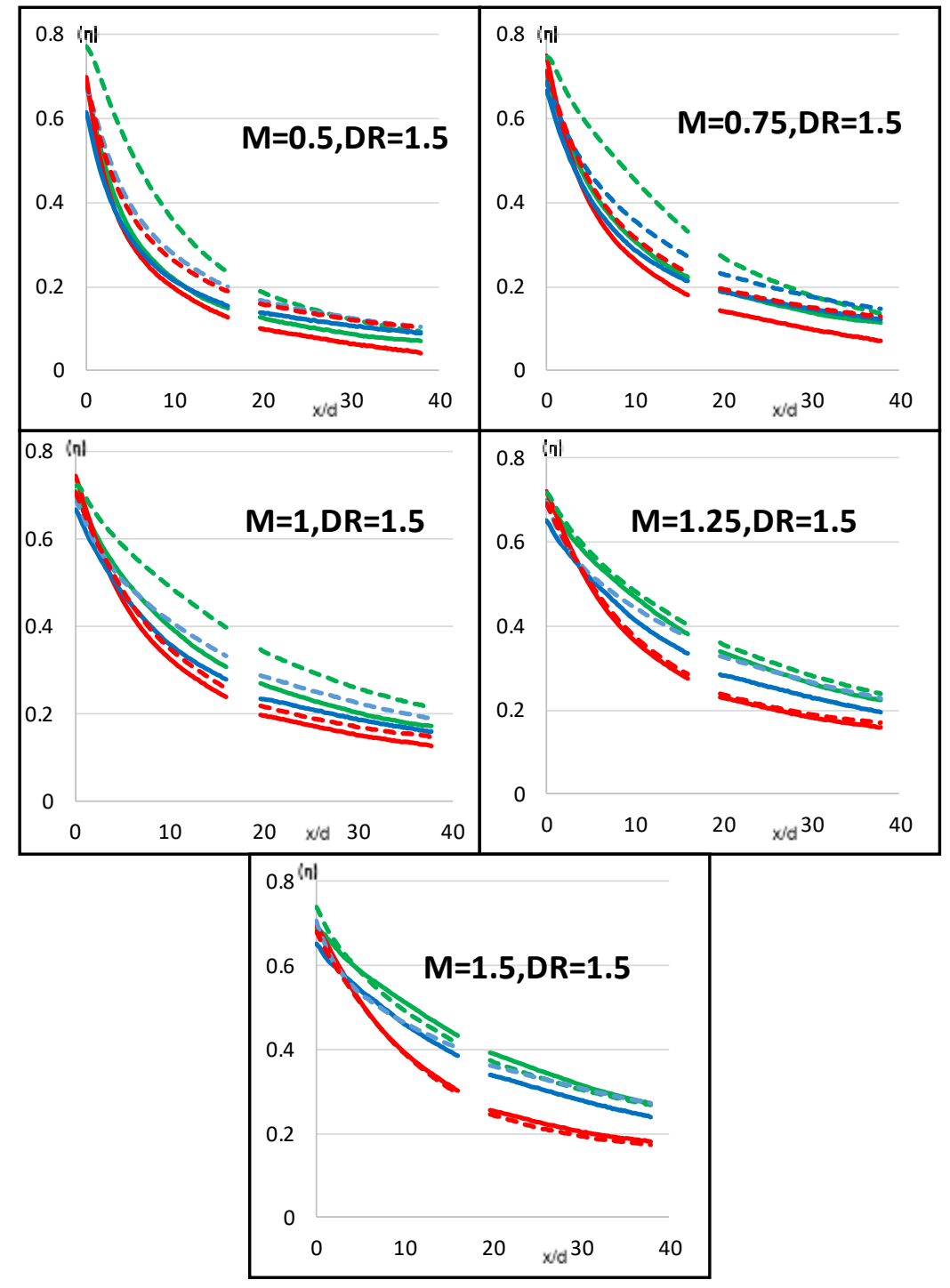

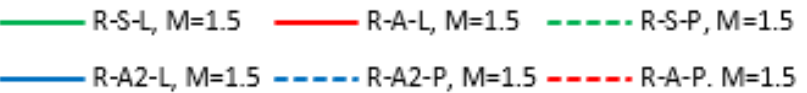

Figure 27:Effect of exit hole shape and the coolant trajectory on film cooling effectiveness for $D R=1.5$ 
Exit Hole Shape \& Trajectory Effect on Film Cooling Effectiveness

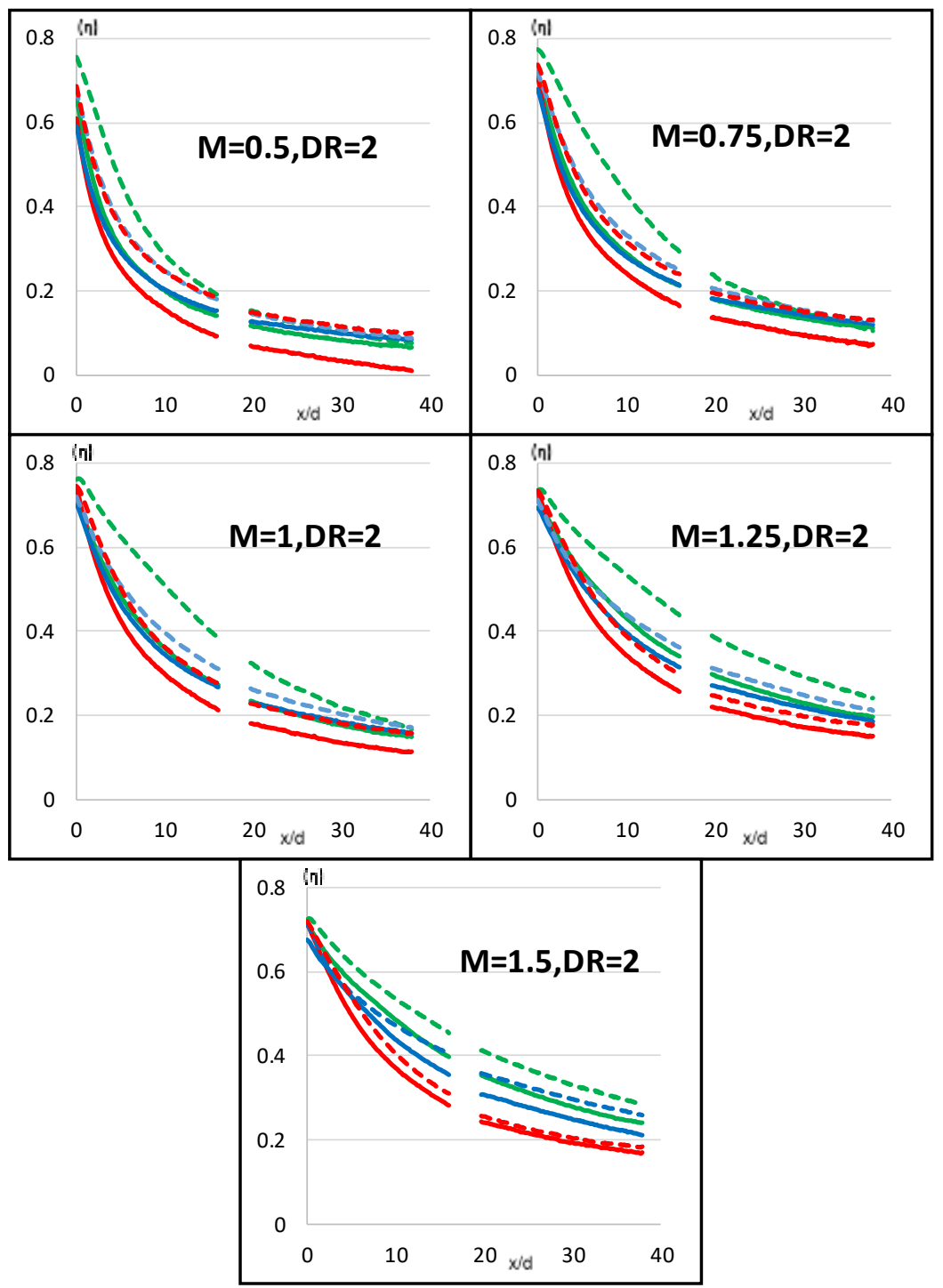

R-S-L, $M=1.5$ R-A-L, $M=1.5 \quad----R-S-P, M=1.5$

Figure 28: Effect of exit hole shape and the coolant trajectory on film cooling effectiveness for $\mathrm{DR}=2$ 


\subsection{Area averaged effectiveness}

Area averaged effectiveness is calculated by averaging out the effectiveness for the middle two holes from $\mathrm{x} / \mathrm{d}=0$ to $\mathrm{x} / \mathrm{d}=37.5$. Figure $28,29 \& 30$ shows the area averaged effectiveness for $\mathrm{DR}=1,1.5$ and 2 respectively. For $\mathrm{DR}=1$ in Figure 28, R-S-P is having the highest area averaged effectiveness for low blowing ratio $(\mathrm{M}<1)$ followed by $\mathrm{R}-\mathrm{A} 2-\mathrm{P}$ however for high blowing ratios $(\mathrm{M} \geq 1) \mathrm{R}-\mathrm{S}-\mathrm{L}$ performs better. In case of $\mathrm{DR}=1.5$ and $\mathrm{DR}=2$ in Figure 29 and 30 respectively, we see that R-S-P outperforms all

the other test cases by area averaged efficiency reaching as high as 0.4 and 0.45 at $\mathrm{DR}=1.5$ and $\mathrm{DR}=2$ respectively for $\mathrm{M}=1.5$. $\mathrm{R}-\mathrm{S}-\mathrm{P}$ is then followed by $\mathrm{R}-\mathrm{A} 2-\mathrm{P}$. 


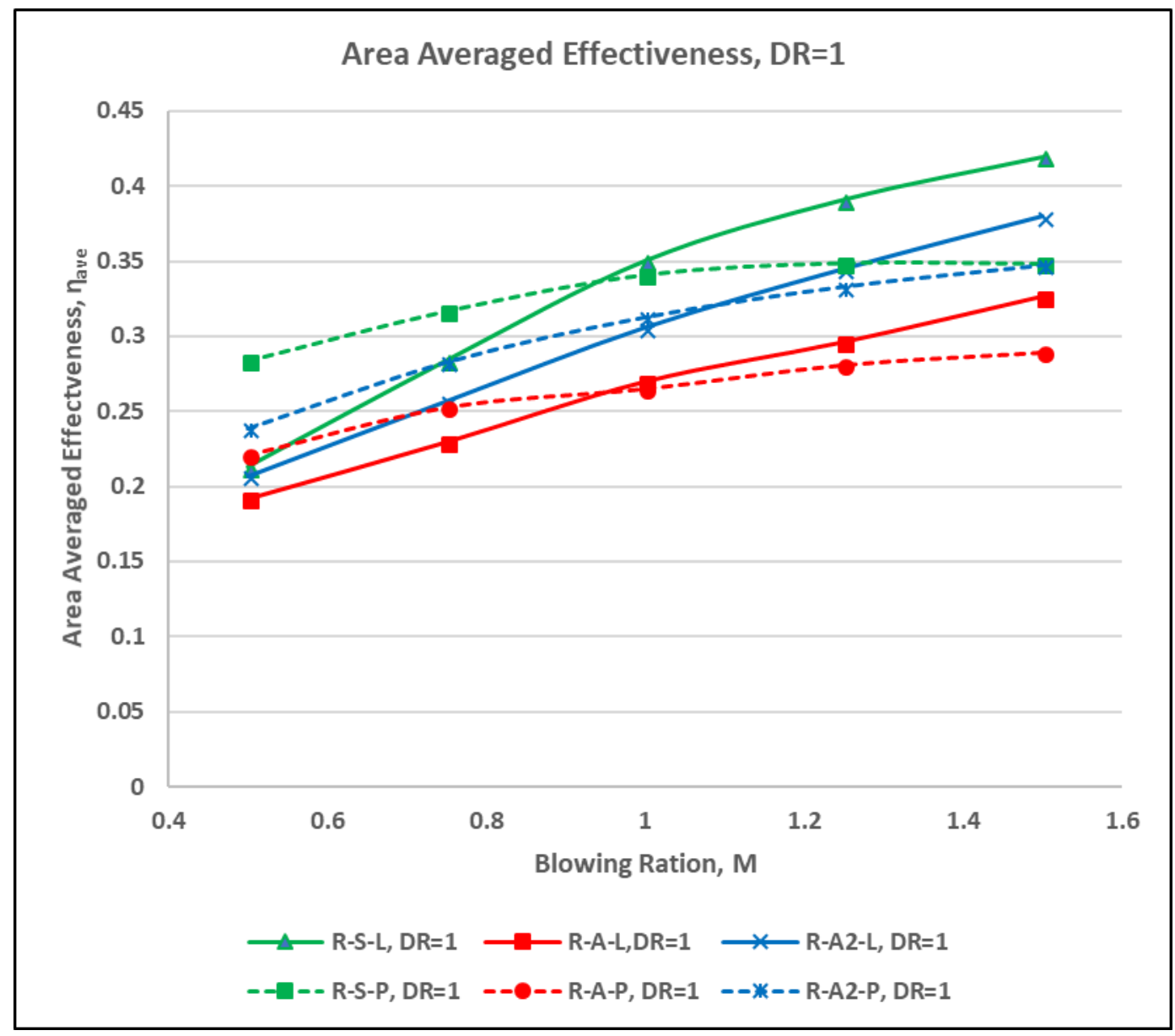

Figure 29:Area averaged effectiveness for $D R=1$ 


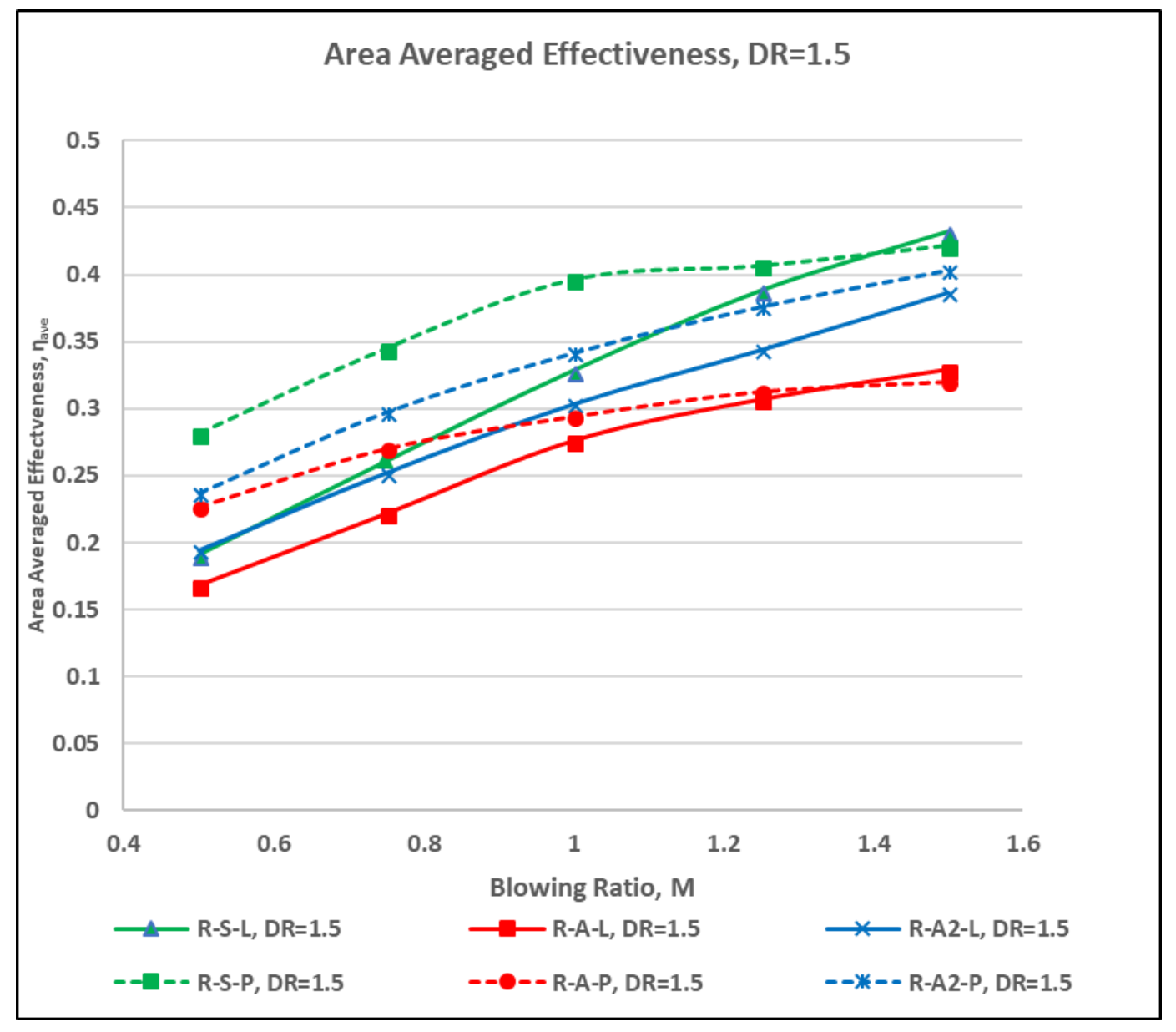

Figure 30:Area averaged effectiveness for $D R=1.5$ 


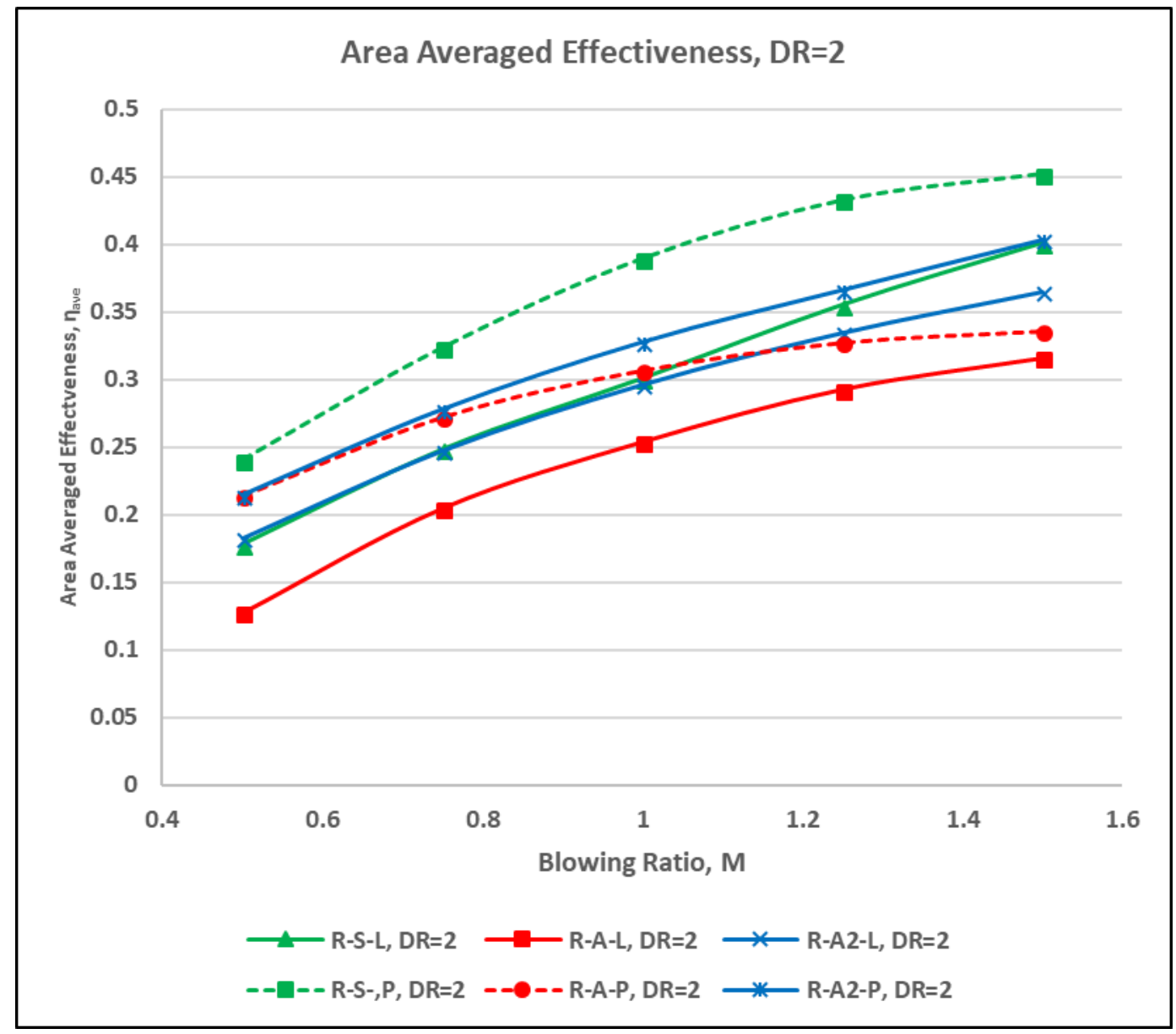

Figure 31: Area averaged effectiveness for $D R=2$ 


\subsection{Exit hole shape and coolant trajectory effect on Discharge Coefficient}

Discharge coefficient data is also acquired for all the six shapes. Figure 31 presents the discharge coefficient $\mathrm{Cd}$ against blowing ratios and different pressure ratio. It must be noted that in general we see that the projectile design (R-S-P, R-A-P, R-A2-P) has a lower discharge coefficient as compared to its Linear counterpart (R-S-L, R-A-L, R-A2L) because of the longer distance the coolant has to travel. This results in greater pressure loss ultimately resulting in high coolant pressure requirement at the inlet plenum. However, if we compare R-S-L with R-A-L \& R-A2-L or R-S-P with R-A-P \& R-A2-P, we see that annular design has a better discharge coefficient than the slot design because of greater exit to inlet area ratio resulting in less pressure requirement at the inlet plenum. Overall, R-S-P has the lowest discharge coefficient and highest-pressure ratio because of lower exit to inlet area ratio and larger coolant trajectory length. This might be the reason of its high effectiveness as this specific design is forcing the coolant to remain attached to the surface. It is worth noting that R-S-P can be recommended in gas turbine having sufficient coolant pressure. 


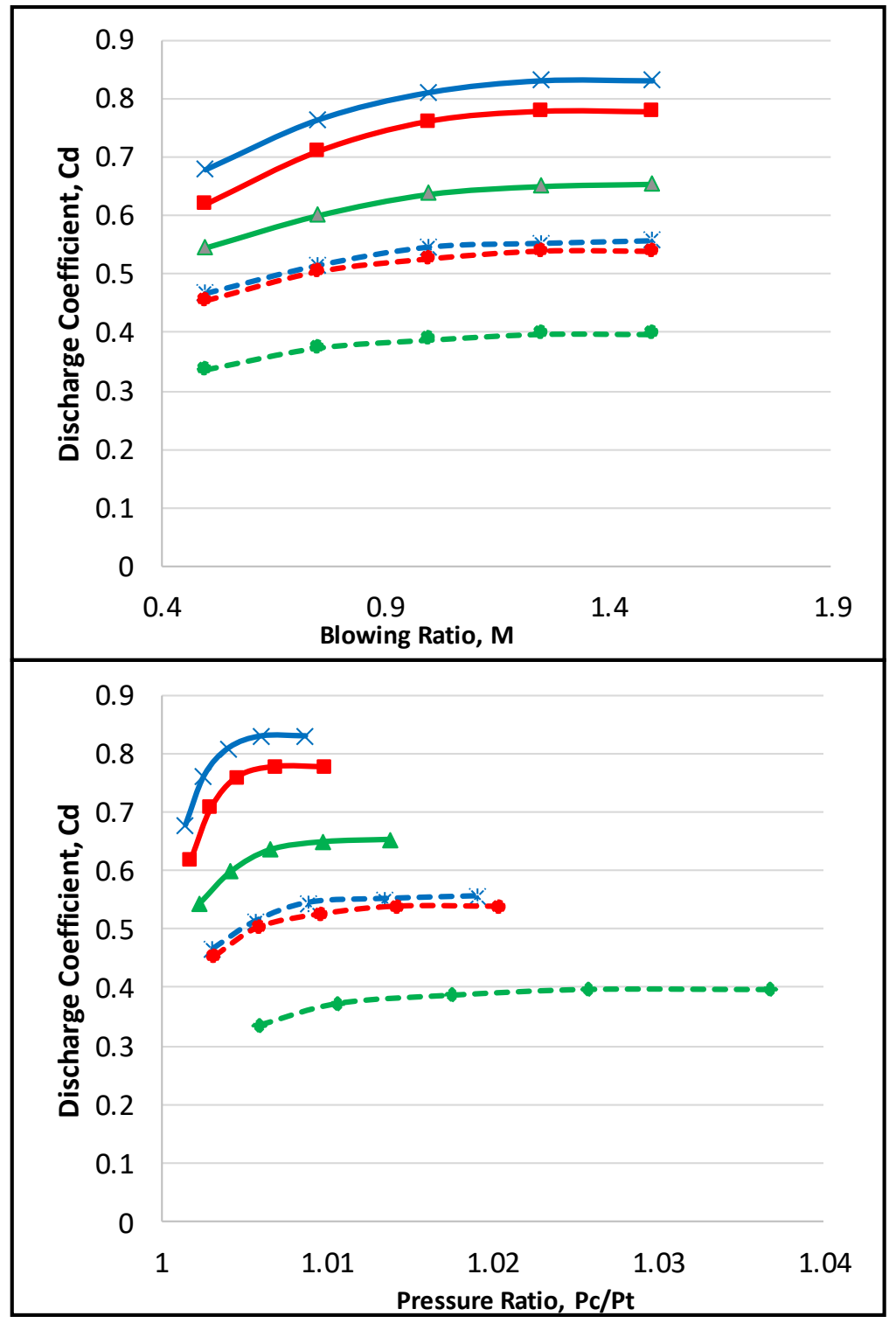

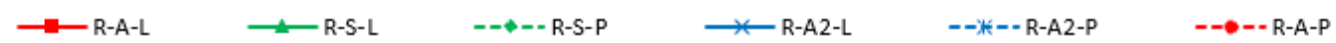

Figure 32: Discharge Coefficient variation with blowing ration and pressure ratio for all the plates 


\subsection{Correlation for Single Row Shaped Holes}

To provide the designer an easy approach in calculating the film cooling effectiveness for all the six test cases, a correlation has been developed that takes into account all the necessary parameters like blowing ratio(M), Density Ratio(DR) and distance (x/d). Correlation for two ranges are developed: (a) Full Range Correlation (b) Correlation for $\mathrm{x} / \mathrm{d} \geq 5$. Eq 5 gives the correlation for the proposed designs:

$$
\eta_{\text {avg }}=K \frac{M^{c 2} D R^{c 3}}{\left(\frac{x}{d}\right)^{c 1}}
$$

Equation 5 can be further linearized as Eq 6:

$$
\ln \eta_{\text {avg }}=\ln K+c 2 \ln (M)+c 3 \ln (D R)-c 1 \ln \left(\frac{x}{d}\right)
$$

Coefficients for the above linearized equation were determined by multiple regression analysis using Minitab ${ }^{\circledR} 18$. Table $3 \& 4$ gives the coefficients for full range and $\mathrm{x} / \mathrm{d} \geq 5$ respectively. As linear models were used to conduction linear regression analysis, the coefficient of determination $\left(\mathrm{R}^{2}\right)$ can be used to statistically explain the percentage of the variation in averaged effectiveness by the regression model in the pre-defined parameter range. As the full range correlation didn't give a very accurate result for film cooling effectiveness especially for R-S-P with $\mathrm{R}^{2}=0.79$, therefore correlation for $\mathrm{x} / \mathrm{d} \geq 5$ was also proposed which gives much accurate results with better values for $\mathrm{R}^{2}=0.87$. Appendix $\mathrm{C}$ contains all the curves for regression analysis for the six test cases. 


\begin{tabular}{|l|c|c|c|c|c|}
\hline & $\mathbf{K}$ & $\mathbf{C 1}$ & $\mathbf{C 2}$ & $\mathbf{C 3}$ & $\mathbf{R}^{2}$ \\
\hline R-S-L & 0.90 & 0.40 & 0.85 & -0.22 & 0.89 \\
\hline R-A-L & 0.95 & 0.52 & 0.87 & -0.276 & 0.85 \\
\hline R-S-P & 0.90 & 0.40 & 0.54 & 0.084 & 0.79 \\
\hline R-A2-L & 0.77 & 0.38 & 0.70 & -0.09 & 0.91 \\
\hline R-A2-P & 0.77 & 0.36 & 0.57 & 0.02 & 0.87 \\
\hline R-A-P & 0.77 & 0.44 & 0.38 & 0.14 & 0.90 \\
\hline
\end{tabular}

Table 3: Full range correlation constants

\begin{tabular}{|c|c|c|c|c|c|}
\hline & $\mathbf{K}$ & $\mathbf{C 1}$ & $\mathbf{C 2}$ & $\mathbf{C 3}$ & $\mathbf{R}^{\mathbf{2}}$ \\
\hline R-S-L & 1.58 & 0.58 & 0.95 & -0.25 & 0.96 \\
\hline R-A-L & 1.88 & 0.74 & 0.97 & -0.31 & 0.90 \\
\hline R-S-P & 1.77 & 0.62 & 0.63 & 0.06 & 0.87 \\
\hline R-A2-L & 1.25 & 0.54 & 0.77 & -0.12 & 0.98 \\
\hline R-A2-P & 1.26 & 0.52 & 0.65 & 0.001 & 0.94 \\
\hline R-A-P & 1.32 & 0.62 & 0.42 & 0.14 & 0.98 \\
\hline
\end{tabular}

Table 4: Correlation constants for $x / d \geq 5$ 


\section{CONCLUSION}

\subsection{Blowing ratio effect}

Effect of blowing ratio is pretty much the same for all the test plates. For R-S$\mathrm{L}, \mathrm{R}-\mathrm{A}-\mathrm{L}$ and R-A2-L a continuous increase in effectiveness is observed at all the density ratios. However, the increase in effectiveness for R-A-L is very little as compared to R-SL and R-A2-L. For R-S-P and R-A2-P effectiveness increases with increase in blowing ratio till $\mathrm{M}=1$ for $\mathrm{DR}=1$ and $\mathrm{DR}=1.5$. However, for $\mathrm{M}>1$ for $\mathrm{DR}=1$ and $\mathrm{DR}=1.5$ there is little or no increase with increase in blowing ratio. At DR=2 both R-S-P and R-A2-P has continuous increase in effectiveness with increase in blowing ratio. R-A-P has very little increase with increase in blowing ratio at all density ratios.

\subsection{Density ratio effect}

For linear and projectile trajectory cases, density ratio effect is insignificant.

\subsection{Exit hole shape and coolant trajectory effect on film effectiveness}

Comparing Slot with annulus and annulus2, we conclude that slot is still the most effective exit shape. Slot design coupled with projectile trajectory gives the best design with increase in effectiveness up to a maximum of $30 \%$ as compared to reference case (R-S-L).

\subsection{Area averaged effectiveness}

Area averaged effectiveness for R-S-P is the highest as compared to all the cases except at $\mathrm{DR}=1 \& \mathrm{M}>1$. 


\subsection{Exit hole shape and coolant trajectory effect on Discharge Coefficient}

Annulus design has a better discharge coefficient as compared to slot design because of greater area ratio. If the trajectories are compared then projectile trajectory case has lower discharge coefficient than its linear counter part due to greater trajectory length. Combining the effect of area ratio and trajectory, we see that R-S-P has the lowest discharge coefficient and the highest-pressure ratio under the same blowing ratio $(\mathrm{M})$ as compared to all the other test cases.

\subsection{Correlation for Single Row Shaped Holes}

Correlation for single row shaped hole is developed which predicts the effectiveness to a reasonable accuracy. 


\section{REFERENCES}

[1]. Han, J. C., 2013, "Fundamental Gas Turbine Heat Transfer," ASME J. Thermal Sci. Eng. Appl., 5(2), p. 021007.

[2]. Goldstein, R. J., 1971, "Film Cooling," Advances in Heat Transfer, Vol. 7, Irvine, T. F., Jr and Hartnett, J. P., eds., Academic Press, New York, pp. 321-379.

[3] Ekkad, S. V., and Han, J. C., 2013, "A Review of Hole Geometry and Coolant Density Effect on Film Cooling," Proceedings of the 2013 Summer Heat Transfer Conference, Minneapolis, Minnesota, July 14-19, Paper No. HT2013-17250

[4] Bunker R.S., 2005, “A Review of Shaped Hole Turbine Film-Cooling Technology”. ASME. J. Heat Transfer.;127(4):441-453

[5] Eckert, E. R. G., Eriksen, V. L., Goldstein, R. J., and Ramsey, J. W., 1970, "Film Cooling Following Injection through Inclined Circular Tubes," Israel Journal of Technology, 8, pp. 145.

[6] Goldstein, R. J., Eckert, E. R. G., and Burggraf, F., 1974, "Effects of Hole Geometry and Density on 3-Dimensional Film Cooling," International Journal of Heat and Mass Transfer, 17, pp. 595-607.

[7] Makki, Y.H., and Jakubowski, G.S., 1986, “An Experimental Study of Film Cooling from Diffused Trapezoidal Shaped Holes," Proceedings of AIAA and ASME Joint Thermophysics and Heat Transfer Conference, 86-1326, Boston, Massachusetts, USA. 
[8] Thole, K., Gritsch, M., Schulz, A., and Wittig, S., 1998, "Flowfield Measurements for Film-Cooling Holes with Expanded Exits," Journal of Turbomachinery, 120(2), 327-336.

[9] Gritsch, M., Schulz, A., and Wittig, S., 1998b, “Adiabatic Wall Effectiveness Measurements of Film-Cooling Holes with Expanded Exits," Journal of Turbomachinery, 120(3), 549-556.

[10] Hyams, D.G, Leylek, J.H., 2000, “A Detailed Analysis of Film Cooling Physics: PartIII-Streamwise Injection with Shaped Hole," ASME J. of Turbomachinery, Vol. 122, pp122-132

[11] Sargison, J.E., Guo, S.M., Oldfield, M.L.G., Lock, G.D., and Rawlinson, A.J., 2002, “A Converging Slot-Hole Film-Cooling Geometry_Part 1: Low-Speed Flat-Plate Heat Transfer and Loss". ASME. J. Turbomach.;124(3):453-460.

[12] Sargison, J.E., Guo, S.M., Oldfield, M.L.G., Lock, G.D., and Rawlinson, A.J.,2001, “A Converging Slot-Hole Film-Cooling Geometry Part 2 - Transonic Nozzle Guide Vane Heat Transfer and Loss". IGTI Turbo Expo, New Orleans, Paper 2001-GT-0127

[13] Moser, S., Ivanisin, M., Woisetschläger, J., Jericha, H., 2000, "Novel Blade Cooling Engineering Solution”. IGTI Turbo Expo, Munich, Paper 2000- GT-242

[14] Fric, T.F., and Campbell, R. P., 2002, "Method for Improving the cooling Effectiveness of a Gaseous Coolant Stream Which Flows Through a Subrtrate, And Related Articles of Manufacture, “US Patent No. 6,383,602.

[15] Bunker, R.S., 2002, "Film Cooling Effectiveness Due to Discrete holes Within a Transverse Surface Slot, “ IGTI Turbo Expo, Amsterdam, Paper GT 2002-30178 
[16] Nasir, H., Acharya, S., and Ekkad, S., 2001, “Film Cooling From a Single Row of Cylindrical Angled Holes With Triangular Tabs Having Different Orientations," IGTI Turbo Expo, New Orleans, Paper 2001-GT-0124.

[17] Lu, Y., Dhungel, A., Ekkad, S.V., and Bunker, R.S., 2007a, "Effect of Trench Width and Depth on Film Cooling from Cylindrical Holes Embedded in Trenches," Proceedings of ASME Turbo Expo, GT2007-27388, Montreal, Canada.

[18] Lu, Y., Dhungel, A., Ekkad, S.V., and Bunker, R.S., 2007b, "Film Cooling Measurements for Cratered Cylindrical Inclined Holes," Proceedings of ASME Turbo Expo, GT2007-27386, Montreal, Canada.

[19] Lee, K.-D., and Kim, K.-Y., 2012, “Performance Evaluation of a Novel Film Cooling Hole,” ASME J. Heat Transfer, 134(10), p. 101702.

[20] Yang, X., Liu, Z., and Feng, Z., 2015, "Numerical Evaluation of Novel Shaped Holes for Enhancing Film Cooling Performance," ASME J. Heat Transfer, 137(7), p. 071701. [21] An, B., Liu, J., Zhou, S., 2017, "Geometrical Parameter Effects on Film-Cooling Effectiveness of Rectangular Diffusion Holes". ASME. J. Turbomach. 2017;139 [22] Abdala, A.M.M., Elwekeel, F.N.M., 2016, "CFD Simulations of Film Cooling Effectiveness and Heat Transfer For Annular Film Hole" Arab J Sci Engineering (2016) $41: 4247-4262$

[23] Gritsch, M., Schulz, A., and Wittig, S., 1998c, "Discharge Coefficient Measurements of Film Cooling Holes with Expanded Exits," Journal of Turbomachinery, 120(3), 557563. 
[24] Kohli, A., Thole, K.A., 1997, “A CFD Investigation on the Effect of Entrance Flow Conditions in Discrete Film Holes," Proceedings of ASME 32nd National Heat Transfer, $12,223-232$.

[25] Kohli, A.A., Thole, K.A., 1998, "Entrance Effects on Diffused Film-Cooling Holes. ASME. Turbo Expo": Power for Land, Sea, and Air, Volume 4: Heat Transfer; Electric Power; Industrial and Cogeneration (): Paper No. 98-GT-402, pp. V004T09A070

[26] Burd, S.W., Simon, T.W., 1999, "Measurements of Discharge Coefficients in Film Cooling”. ASME. J. Turbomach.;121(2):243-248.

[27] Taslim, M. E., and Ugarte, S., 2004. "Discharge Coefficient Measurements for Flow Through Compound-Angle Conical Holes with Cross-Flow," International Journal of Rotating Turbomachinery, 10, pp. 145-153.

[28] Zuniga, H.A., Krishnan, V., Sleiti, A.K., Kapat, J.S., Bharani, S., 2005, “Discharge Coefficient and Effectiveness Measurement for Conical Shaped Film Cooling Holes”. ASME. ASME proceedings, Heat Transfer, Part A, Paper No. IMECE2005-81713, pp. $503-512$

[29] Zhang, J.Z., Zhu, X.D., Huang, Y., Wang, C.H., 2017, "Investigation on film cooling performance from a row of round-to-slot holes on flat plat", International Journal of Thermal Sciences Volume 118, Pages 207-225

[30] Han, J. C., and Rallabandi, A., 2010, "Turbine Blade Film Cooling Using PSP Technique," Frontiers in Heat and Mass Transfer (FHMT), 1, pp. 013001. 
[31] Haven, B.A., Yamagata, D.K., Kurosaka, M., Yamawaki, S., Maya, T., 1997, “Anti kidney pair of vortices in shaped holes and their influence on film cooling effectiveness". Proc ASME Turbo Expo 1997. Paper 97-GT-45,

[32] Chen, A.F., Li, S., Han, J., 2014, "Film Cooling With Forward and Backward Injection for Cylindrical and Fan-Shaped Holes Using PSP Measurement Technique". ASME. Turbo Expo: Power for Land, Sea, and Air, Volume 5B: Heat Transfer, Paper No. GT2014-26232, pp. V05BT13A042

[33] Bashir, M. H., Shiau, C. C., Han, J. C., 2017, “Film Cooling Effectiveness for threerow compound angle hole design on flat plate using PSP technique," International Journal of Heat and Mass Transfer, 115, pp.918-929.

[34] Zhang, L., and Jaiswal, R., 2001, "Turbine nozzle endwall film cooling study using Pressure-Sensitive Paint,” ASME J. Turbomach., 123(4), pp. 730-738.

[35] Kline, S. J., and McClintock, F. A., 1953, "Describing Uncertainties in a Single Sample Experiment," Mechanical Engineering (ASME), 75, pp. 3-8. 


\section{APPENDIX A}

Figure A1: Full range and $\mathrm{x} / \mathrm{d} \geq 5$ regression analysis curve for R-S-L

Figure A2: Full range and $\mathrm{x} / \mathrm{d} \geq 5$ regression analysis curve for $\mathrm{R}-\mathrm{A}-\mathrm{L}$

Figure A3: Full range and $\mathrm{x} / \mathrm{d} \geq 5$ regression analysis curve for $\mathrm{R}-\mathrm{A} 2-\mathrm{L}$

Figure A4: Full range and $\mathrm{x} / \mathrm{d} \geq 5$ regression analysis curve for R-S-P

Figure A5: Full range and $\mathrm{x} / \mathrm{d} \geq 5$ regression analysis curve for R-A-P

Figure A6: Full range and $\mathrm{x} / \mathrm{d} \geq 5$ regression analysis curve for $\mathrm{R}-\mathrm{A} 2-\mathrm{P}$ 

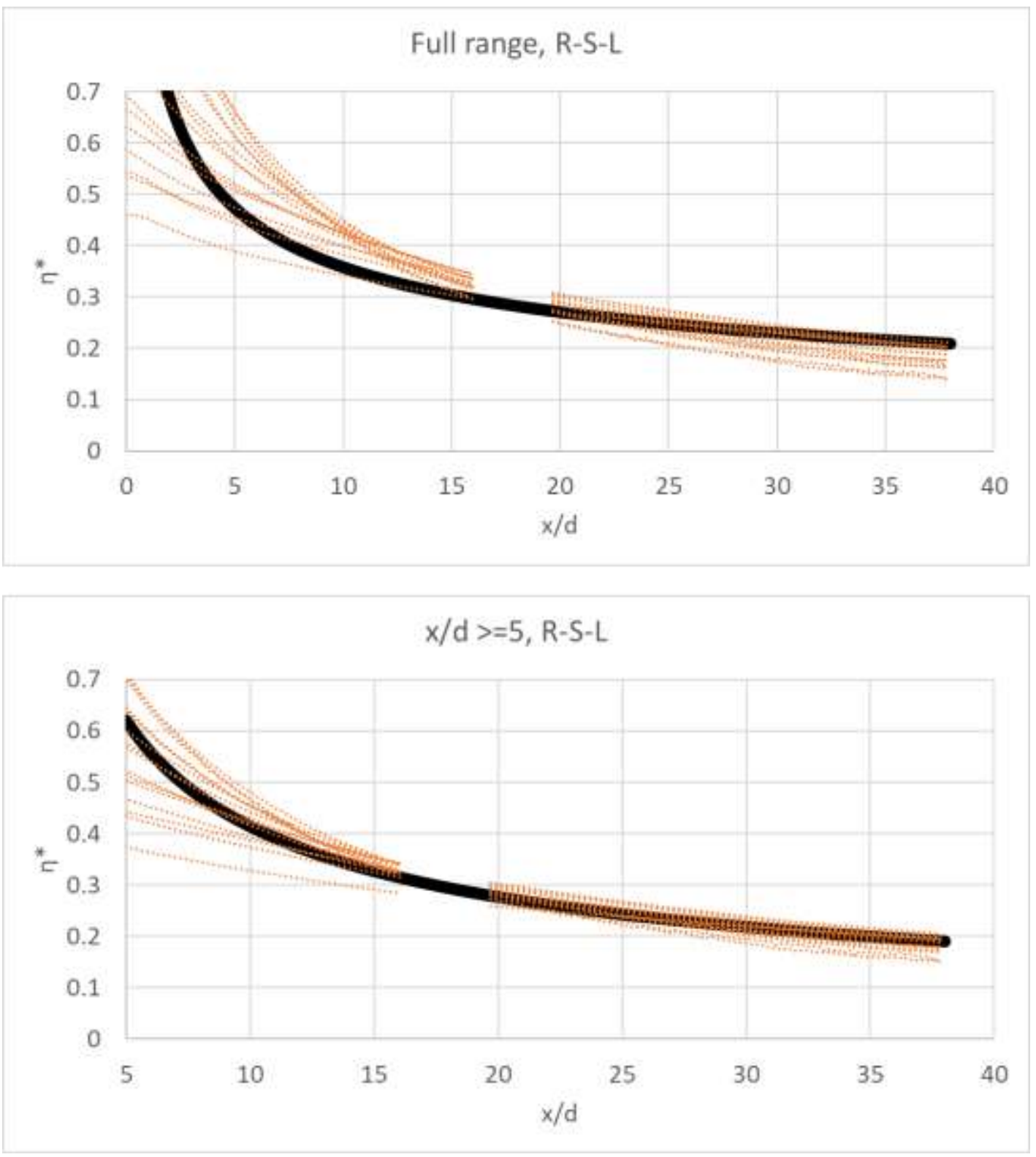

Figure A1: Full range and $x / d \geq 5$ regression analysis curve for $R-S-L$ 

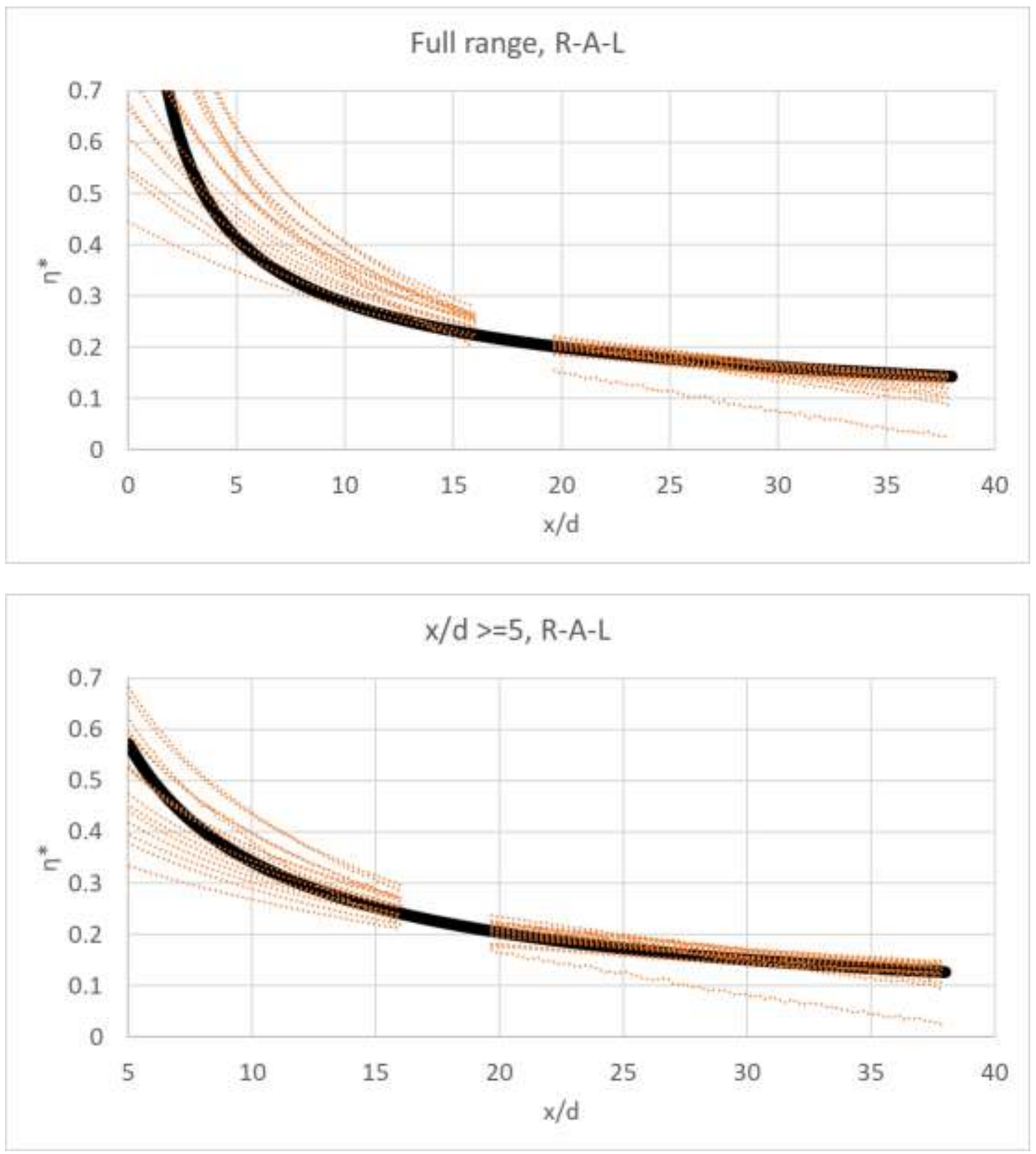

Figure A2: Full range and $x / d \geq 5$ regression analysis curve for $R-A-L$ 

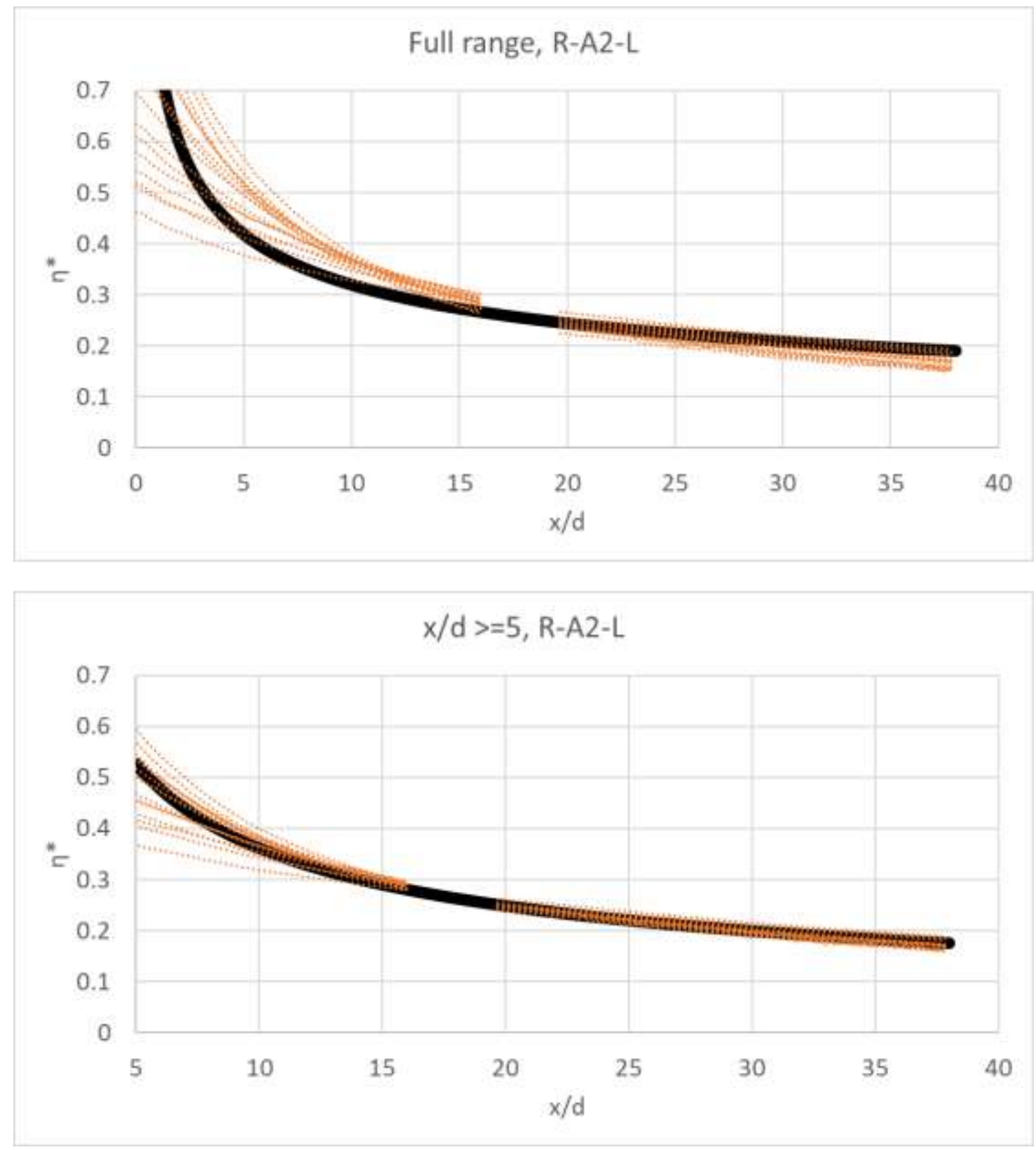

Figure A3: Full range and $x / d \geq 5$ regression analysis curve for $R-A 2-L$ 

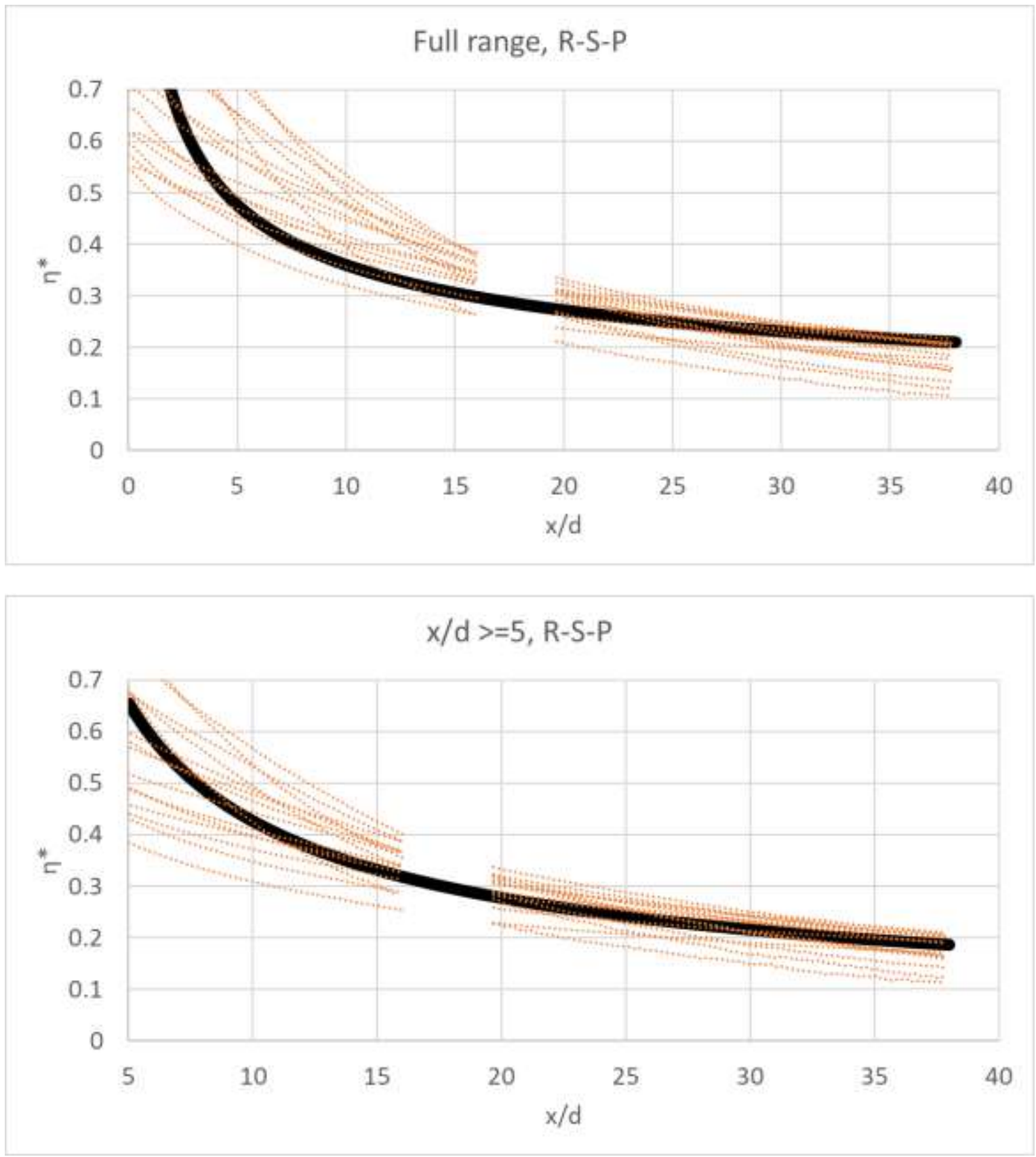

Figure A4: Full range and $x / d \geq 5$ regression analysis curve for $R-S-P$ 

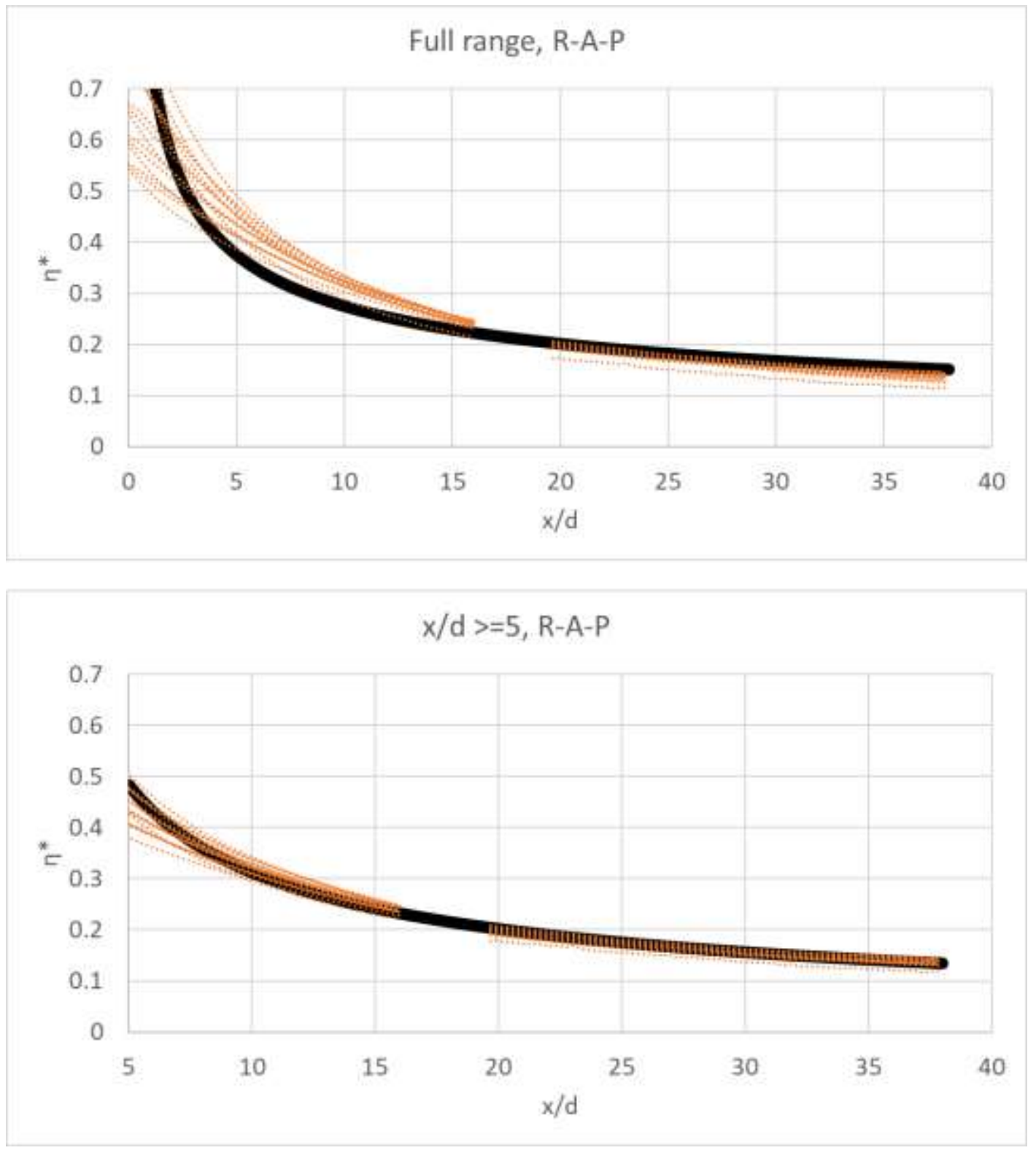

Figure A5: Full range and $x / d \geq 5$ regression analysis curve for $R-A-P$ 

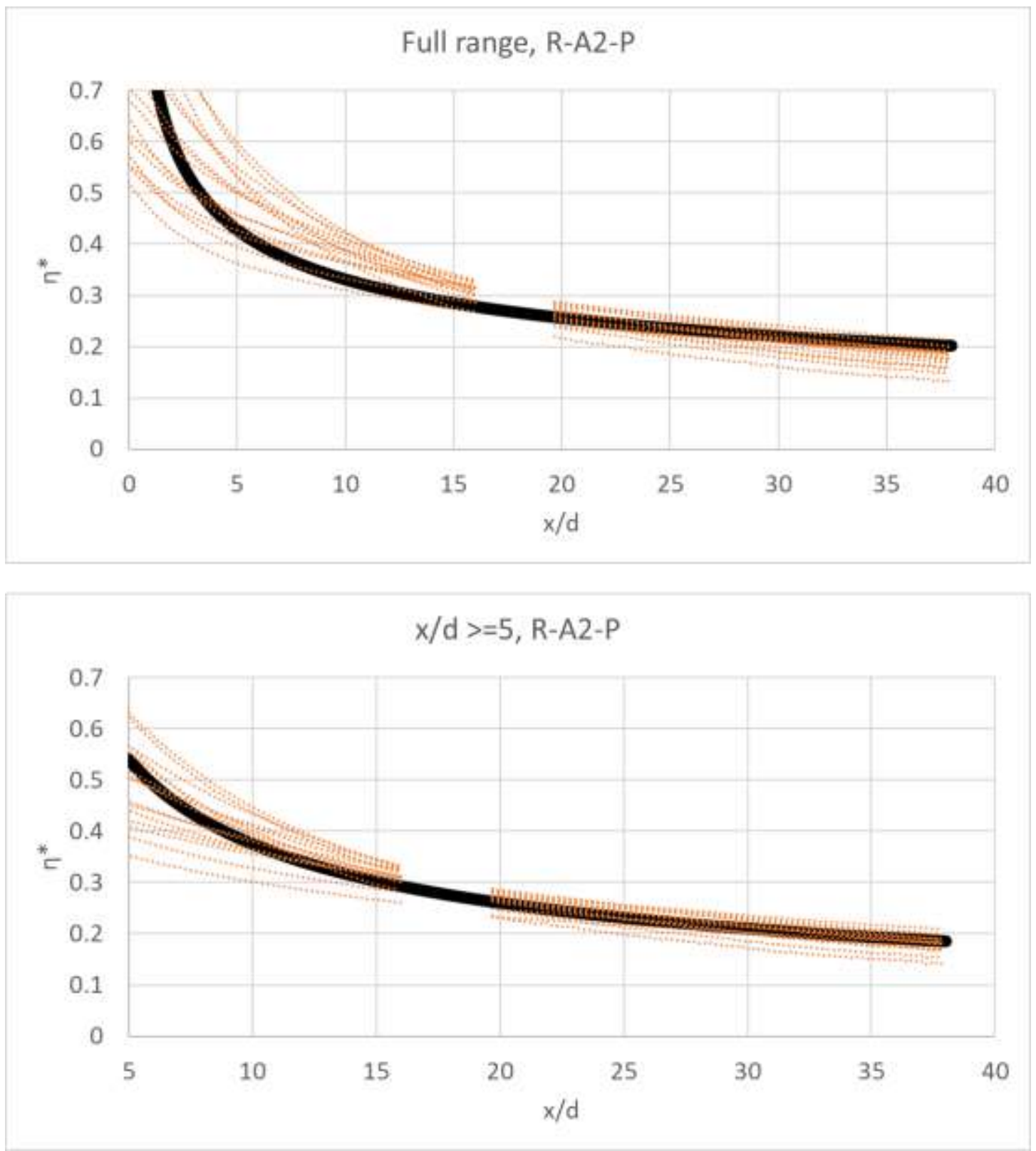

Figure A6: Full range and $x / d \geq 5$ regression analysis curve for $R-A 2-P$ 